\title{
QSWAT Model Calibration and Uncertainty Analysis for Stream Flow Simulation in the Patapur Micro-Watershed Using Sequential Uncertainty Fitting Method (SUFI-2)
}

\author{
B.D. Premanand ${ }^{1}$, U. Satishkumar ${ }^{1}$, B. Maheshwara Babu ${ }^{1}$, S.K. Parasappa ${ }^{2}$, \\ Mallikarjuna M. Dandu ${ }^{3}$, Ibrahim Kaleel ${ }^{4}$, N.L. Rajesh ${ }^{5}$ and S.A. Biradar ${ }^{6}$ \\ ${ }^{1}$ Department of Soil and Water Conservation Engineering, College of Agricultural \\ Engineering, UAS, Raichur, Karnataka, India \\ ${ }^{2}$ Department of Agricultural Engineering, College of Agriculture, \\ UAS, Dharwad, Karnataka, India \\ ${ }^{3}$ Department of Agricultural Engineering, College of Agriculture, B' Gudi, \\ UAS, Raichur, Karnataka, India \\ ${ }^{4}$ PFDC-WTC, PJTSAU, Rajendranagar Hyderbad, India \\ ${ }^{5}$ Department of Soil Science and Agricultural Chemistry, College of Agriculture, \\ UAS, Raichur, Karnataka, India \\ ${ }^{6}$ KVK, Vijayapaur, UAS, Dharwad, Karnataka, India \\ *Corresponding author
}

\begin{tabular}{|l|}
\hline Key w o r d s \\
Patapur micro- \\
watershed, Soil and \\
Water Assessment \\
Tool (SWAT)
\end{tabular}

\section{Key words}

Patapur microTool (SWAT)

Accepted: Available Online: pril 2018

\section{A B S T R A C T}

The Patapur micro-watershed situated in semi-arid region needs effective management of resources for sustainable agriculture. The Soil and Water Assessment Tool (SWAT), a semi distributed physically based model, was chosen and set up in the Patapur micro-watershed for hydrologic modeling. SWAT-CUP (SWAT-Calibration and Uncertainty Programs) was used for model calibration, sensitivity and uncertainty analysis, following the Sequential Uncertainty Fitting (SUFI2 ) technique. The model calibration was performed for the period (2009-2014), with initial 3 years of warm up (2009-2012), then, the model was validated for the subsequent 2 years of data (20142006). To assess the competence of model calibration and uncertainty, two indices, the p-factor (observations bracketed by the prediction uncertainty) and the r-factor (achievement of small uncertainty band), were taken into account. The results had shown that p-factor for daily, monthly and annual time step were $0.07(7 \%), 0.11(11 \%), 1.0(100 \%)$, respectively while r-factor for daily, monthly and annual were $0.07(7 \%), 0.33(33 \%)$ and $0.0(0 \%)$, respectively, while during the validation $\mathrm{p}$ factor and $\mathrm{r}$-factor for daily, monthly and annual were $0.85,0.17$ and 1 , respectively. Whereas r-factor for daily, monthly and annual time step were 0.05 (5\%), 0.24(24\%) and 0 , respectively. After a rigorous calibration and validation, the goodness of fit was further assessed through the use of the coefficient of determination $\left(\mathrm{R}^{2}\right)$ and the Nash-Sutcliffe efficiency (NS) between the observed and the final simulated values. The results indicated that $R^{2}$ and NS were 0.88 and 0.87 , respectively, during the daily calibration. The validation also indicated a satisfactory performance with $\mathrm{R}^{2}$ of 0.63 and NS of 0.64 . The results would be useful to the hydrological community, water resources managers involved in agricultural water management and soil conservation, as well as to those involved in mitigating natural hazards such as droughts and floods. 


\section{Introduction}

Hydrologic models are more and more widely applied by hydrologists and resources managers as a tool to understand and manage natural and human activities that affect watershed systems. The successful application of a hydrologic model depends on how well the model is calibrated (Duan et al., 1992). Hydrologic models, even those physicallybased models, often contain parameters that cannot be measured directly due to measurement limits and scale issues (Beven, 2000). These parameters need to be estimated through an inverse method by calibration so that observed and predicted output values are in agreement. Before the widespread availability of high speed computers, hydrologic practitioners utilized knowledge of the watershed and experience with the model to adjust the parameters through a manual trial and error procedure (Gupta et al., 1999). This approach to calibration is subjective and labour intensive. Automatic calibration methods, which are objective and relatively easy to implement with high speed computers, have become more popular in recent years (Vrugt et al., 2003). There are many physically-based watershed models that have been successfully applied in practical hydrologic modelling problems. However, since running these models is time intensive, it is nearly impossible to test the optimization algorithms for the complex models. In this study one complex distributed hydrologic model-Soil and Water Assessment Tool (SWAT) (Arnold et al., 1998) was selected to calibrate and validate for the Patapur microwatershed.

The technique of model calibration is a challenging and rigorous process, which depends on the number of input parameters, model complexity as well as iterations (Vanrolleghem et al., 2003). SA and UA are essential processes to reduce the uncertainties imposed by the variations of model parameters and structure (Gupta et al., 2006; Srivastava et al., 2013c; Wagener and Gupta 2005). Recently developed calibration and uncertainty analysis techniques for watershed models include: MCMC (Markov Chain Monte Carlo) method (Vrugt et al., 2008), GLUE (Generalized Likelihood Uncertainty Estimation) (Beven and Binley, 1992), ParaSol (Parameter Solution) (Yang et al., 2008), and SUFI-2 (Sequential Uncertainty Fitting) (Abbaspour et al., 2004). These techniques (GLUE, Parasol, SUFI-2 and MCMC) have been linked to SWAT model through SWAT-CUP algorithm (Abbaspour $e t$ al., 2007), and enable SA and UA of model parameters as well as structure (Rostamian et al., 2008). Studies on model calibration and UA have emphasized and confirmed that SWAT model is an effective tool in managing water resources (Tang et al., 2012). Abbaspour et al., (2004) and Yang et al., (2008) applied the SUFI-2 technique for evaluation of SWAT model. The SUFI-2 technique needs a minimum number of model simulations to attain a high-quality calibration and uncertainty results (Yang et al., 2008). With this background, the main objective of this study was to simulate the stream flow of the Patapur micro-watershed using SWAT model integrated with model calibration and uncertainty analysis by means of SUFI-2 algorithm and to evaluate its applicability for Patapur micro-watershed. This modeling study also provides support to water resource managers in effectively planning and managing agricultural water resources, soil erosion, as well as natural disasters.

\section{Materials and Methods}

\section{Study Area}

The present study was carried out in the Patapur micro watershed (WS-Code: 4D3A4B1e) named after two villages (Patapur 
and Goladinni) found near the watershed, covers a total geographical area of 488.75 ha, which is part of the Tungabhadra sub basin and falls within the North-Eastern dry zone (Zone-2 of Region-1) of Karnataka and lies between $16^{\circ} 07^{\prime} 35.9^{\prime \prime} \mathrm{N}$ latitude and $76^{\circ} 51^{\prime}$ 33.3" E longitudes to $16^{\circ} 08^{\prime} 22.3^{\prime \prime} \mathrm{N}$ latitude and $76^{\circ} 53^{\prime} 27.7^{\prime \prime}$ E longitudes with an average elevation of $460 \mathrm{~m}$ above mean sea level (MSL) altitude in the Raichur district, Karnataka, India. This is located at about 65 $\mathrm{km}$ from the Raichur city on RaichurLingasugur state high way (SH No. 20) Figure 1. The hydrologically delineated Patapur micro watershed considered for this study covered under the Survey of India toposheet of $56 \mathrm{D} / 16(1: 50,000)$. The elevation of the micro watershed ranges from $432 \mathrm{~m}$ to $546 \mathrm{~m}$ above mean sea level (MSL). The minimum elevation of $432 \mathrm{~m}$ found near the outlet where gauging station is existing and the maximum elevation 546 meters is over the hillocks at upstream side of the watershed.

\section{Model description}

The SWAT (Soil and Water Assessment Tool) distributed model was developed jointly by the Agricultural Research Service (ARS) of the United States Department of Agriculture (USDA-ARS) and Agricultural Experiment Station in Temple, Texas. It is a wellrecognized model for predicting water flows, sediment loss and nutrient balances in complex watershed, basin, and even continental-scale assessments with varying soils, land use, and management conditions (Arnold et al., 1998; Srinivasan et al., 1998; Arnold and Fohrer, 2005; Gassman et al., 2007). It is a physically based, continuoustime, long term simulation, limped parameter, deterministic and originated from agricultural models. The model integrates the principal hydrological processes, soil and nutrient transport, and vegetative growth on a spatial and temporal frame, using a daily to an annual time scale. Regression based functions describe the relationship of input and output in SWAT, and a number of static and dynamic variables are created to represent the system boundary and its function/process.

Large watersheds are divided into smaller units based on stream network, soil and land use information. Rainfall is divided into different components, which include evaporation, surface runoff, infiltration, plant uptake, lateral flow, and groundwater recharge. Water in each sub-watershed is stored as: (1) snow at soil surface (not applicable here), (2) moisture content at various soil layers, (3) shallow aquifer and (4) deep aquifer (King et al., 1999). Surface runoff from daily rainfall is estimated with a modification of the soil conservation service (SCS) curve number (CN) method from United States Department of Agriculture-Soil Conservation Service (USDA SCS) (Arnold and Allen, 1996; Neitsch et al., 2005) and peak runoff rates using a modified rational method (Neitsch et al., 2005). Water, soil, and nutrients are routed from sub-watershed outlet to stream channels.

For present study the SCS curve number was adopted to calculate surface runoff volume using the following equation;

$Q_{\text {surf }}=\frac{\left(R_{d a y}-I_{a}\right)^{2}}{\left(R_{d a y}-I_{a}+S\right)}$

Where, $Q_{\text {surf }}$ is the accumulated runoff or rainfall excess $(\mathrm{mm}), R_{d a y}$ is the rainfall depth for the day $(\mathrm{mm}), I_{a}$ is the initial abstractions which includes surface storage, interception and infiltration prior to runoff ( $\mathrm{mm})$, and $S$ is the retention parameter $(\mathrm{mm})$.

$S=25.4\left(\frac{1000}{C N}-10\right)$ 
Where, $C N$ is the curve number for the day.

The initial abstractions, $I_{a}$, is commonly approximated as $0.2 S$ and equation 3.48 becomes

$Q_{\text {surf }}=\frac{\left(R_{d a y}-0.2 S\right)^{2}}{\left(R_{d a y}+0.8 S\right)}$

Runoff will only occur when $R_{d a y}>I_{a}$.

Where, $\mathrm{Q}_{\text {surf }}$ is the accumulated runoff or rainfall excess $(\mathrm{mm}), \mathrm{R}_{\text {day }}$ is the rainfall depth for the day $(\mathrm{mm})$, and $\mathrm{S}$ is retention parameter (mm). Runoff will occur when $\mathrm{R}_{\text {day }}>0.2 \mathrm{~S}$.

The retention parameter varies spatially due to changes in soils, land use, management and slope and temporally due to changes in soil water content.

The Penman-Monteith (Monteith, 1965) method was chosen for calculating potential evapotranspiration (PET) in the present study. SWAT simulates plant growth by using the generic crop growth module from the EPIC (Erosion Productivity Impact Calculator) model (Neitsch et al., 2005).

The crop growth module first calculates the plant growth under optimal conditions, and then computes the actual growth under stresses inferred by water, temperature, nitrogen, and phosphorous deficiency (Luo, et al., 2008). Sediment yield is estimated for each sub-watershed with the Modified Universal Soil Loss Equation (MUSLE) (Williams, 1975). SWAT first estimates runoff volume and peak runoff rate, which are used to calculate the runoff erosive energy and sediment load (Shen et al., 2009).

Sediement yield is estimated for each subbasin with the modified universal soil loss equation (MUSLE) (Williams, 1975). sed $=11.8\left(Q_{\text {surf }} \cdot q_{\text {peak }} \cdot \text { area }_{\text {hru }}\right)^{0.5} \cdot K_{\text {USLE }} \cdot C_{U S L E} \cdot P_{U S L E} \cdot L S_{U S L E} \cdot C R F G$

Where sed is the sediment yield on a given day (metric tons), area $_{h r u}$ is the area of the HRU (ha), $K_{U S L E}$ is the USLE soil erodibility factor, $C_{U S L E}$ is the USLE cover and management factor, $P_{U S L E}$ is the USLE support practice factor, $L S_{U S L E}$ is the USLE topographic factor and $C F R G$ is the coarse fragment factor. A detailed description of this model is given by Neitsch et al., 2005.

\section{Input data and Model setup}

\section{Soil Properties}

SWAT requires three thematic maps namely soil raster map, Digital Elevation Model (DEM), slope map, land use land cover raster (LULC) were prepared using QGIS software. Further, the weather data file (.txt) soil data file (.xls) and management file (.xls) were prepared in the tabular SWAT format, for the Patapur micro-watershed. The digitized soil map was used in SWAT as raster layer. The digital soil raster map with their mapping units were linked with soil ID and reclassified. The spatial distribution of various soil mapping units along with their nomenclature is shown in the Figure 1. The details of soil physical properties and soil erodibility factor for the Patapur micro-watershed is summarizes in Table 1.

\section{Digital Elevation Model (DEM)}

A digital elevation model (DEM) was extracted from the global US Geological Survey's (USGS) in the format of SRTM (Shuttle Radar Topography Mission) with a spatial resolution of $30 \mathrm{~m} \times 30 \mathrm{~m}$ and resampled to $15 \mathrm{~m} \times 15 \mathrm{~m}$ for ease in data acquisition. The re-sampled DEM was projected to WGS 1984 UTM Zone $43 \mathrm{~N}$ 
(EPSG: 32643) using the raster projections in QGIS before it was imported to QSWAT. The generated DEM is depicted in Figure 2a. The projected map was used for watershed delineation in QSWAT which is an interface in the QGIS to use it in the SWAT model. Further, using DEM map the slope, contour, and relief maps were derived and shown in the Figure 2(b- d). The entire watershed was classified into six slope categories for the watershed as 0-2,2-5,5-10,10-15,15-25 and $>25$ per cent.

\section{Land Use/Land Cover}

The land use map for the year 2015 was created by recording the crop type on each parcel/field of individual farmers by transact survey. The land use other than agricultural crops namely, open scrub, barren land, settlement and roads were created by identifying in the Google image. The digital Google image was geo-referenced by taking control points around and inside the watershed. The above mentioned individual field parcels were digitized using the digitizing tools provided in the QGIS software representing the land use and land cover of each parcel/field Figure 3. The shape file along with attribute table was also prepared in data base format with respect to the above mentioned land use land cover data. The digital LULC raster map was linked to LULC SWAT codes using lookup tables and reclassified according to SWAT coding convention.

The major land use categories of the watershed were agriculture which occupies 64.63 per cent which comprises the agricultural row crops namely, cotton $(25.92 \%)$, pigeon pea $(15.15 \%)$, bajra $(13.23 \%)$ and sunflower $(10.33 \%)$ and forming major percentage of coverage of the watershed. The rest of the area is covered by open scrub (30.18\%), barren land (3.68\%) and settlement $(1.51 \%)$ of the total area of the micro-watershed.

One of the main sets of input for simulating the hydrological processes in SWAT is weather data. The weather data of 37 years (from 01-01-1980 to 31-12-2016) was considered in the present study. The weather input consists of precipitation, relative humidity, solar radiation, temperature and wind speed and weather generator (.dbf) file. The weather data for study periods were prepared in .dbf format and then imported in the SWAT model. The location table of weather data and weather generator file created were uploaded into the SWAT model.

Crop management parameters in SWAT were based on farmers' normal practice in Patapur micro-watershed. The crop pattern is dominated by cotton planted in July and harvested in January followed by pigeon pea planted in July and harvested in November.

Tillage was in the last week of May and nitrogen and phosphorous fertilizers ( $\mathrm{N}$ and $\mathrm{P}$, each $50 \mathrm{~kg}-\mathrm{ha}^{-1}$ ) were applied on second week of July at the time of sowing. A second doze of fertilizer ( $\left(\mathrm{N}\right.$ and $\mathrm{P}$, each $\left.50 \mathrm{~kg}-\mathrm{ha}^{-1}\right)$ was applied to the crops in middle stage of crop growth 120 days after crop planting.

\section{Model initialization}

In defining HRUs, the minor land use/land cover, slope and soil types were ignored by setting a threshold of 20 per cent threshold level for land use, 10 per cent for soil and 20 per cent for slope to avoid unnecessary large number of HRUs in the analysis (Neitsch et al., 2005).

SWAT has been calibrated for daily, monthly and annual time step for streamflow by comparing with the observed streamflow monitored at the outlet of the Patapur micro- 
watershed. Finally, watershed was delineated into 12 sub-watersheds and 106 HRUs by QSWAT.

\section{Sensitivity analysis, calibration and validation of SWAT model}

In the present study, the sensitivity analysis, calibration and validation of SWAT model for stream flow was carried out using the open source software namely, QSWAT Calibration and Uncertainty Program (SWAT-CUP) which is an interface that was developed for SWAT. In this study, the SUFI-2 algorithm was used to investigate sensitivity and uncertainty in stream flow prediction. The SUFI2 method was chosen since, this method is faster, robust and versatile and also, it can supply the widest marginal parameter uncertainty intervals of model parameters among the five approaches. A multiple regression system with Latin hypercube samples by means of objective function values was used in calculating the responsive parameter sensitivities, with the detailed method specified by Yang et al., (2008).Under the SUFI 2, the global sensitivity analysis was considered and analysis was performed and the parameters were finalized based on their ranking of the parameters. The detailed methodology of global sensitivity analysis is explained hereunder.

\section{Global sensitivity analysis}

Global sensitivity analysis performs the sensitivity of one parameter while the values of other related parameters are also keep changing. Global sensitivity analysis uses ttest and p-values to determine the sensitivity of each parameter. The t-stat provides a measure of the sensitivity (larger in absolute values are more sensitive) and the p-values determine the significance of the sensitivity and hence a value close to zero has more significance. Therefore, ranking in both cases (t-stat or $\mathrm{p}$-value) give the same result i.e. a parameter will have the same rank whether it is ranked based on the t-stat or P-value. Global sensitivity analysis was performed after one iteration by selecting 500 numbers of simulations (Abbaspour, 2013).

\section{Uncertainty analysis performance indicators (p-Factor and r- Factor)}

For this reason, Abbaspour et al., (2007 and 2012) suggested using two measures, referred to as the $\mathrm{p}$-factor and the r-factor. The $\mathrm{p}$-factor is the percentage of the measured data bracketed by the 95 per cent prediction boundary often referred to as 95PPU, was used to quantify all the uncertainties associated with the SWAT model. This index provides a measure of the model's ability to capture uncertainties. As all the 'true' processes are reflected in the measurements, the degree to which the 95PPU does not bracket the measured data indicates the prediction error. Ideally, the p-factor should have a value of 1 , indicating 100 per cent bracketing of the measured data, hence capturing or accounting for all the correct processes. The r-factor, on the other hand, is a measure of the quality of the calibration and indicates the thickness of the 95PPU and is the average width of the 95PPU band divided by the standard deviation of the measured variable and varies in the range $0-1$. Its value should ideally be near zero, hence coinciding with the measured data. The combination of $p$ factor and r-factor together indicate the strength of the model calibration and uncertainty assessment. The p- and r-factors are closely related to each other, which indicate that a larger p-factor can be achieved only at the expense of a higher r-factor. After balancing these two factors, and at an acceptable value of the rand p-factors, the calibrated parameter ranges can be generated. The r-factor is given by Eq. (3) (Yang et al., 2008): 


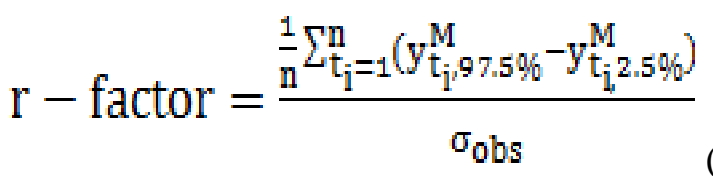

\section{Model performance evaluation}

To evaluate the performance of model, four statistical parameter namely, coefficient of determination $\left(\mathrm{R}^{2}\right)$, the Nash-Sutcliffe efficiency coefficient (NS), root mean square error (RMSE) and percent bias (PBIAS) were used during the calibration and validation periods. To assess the goodness-of-fit of the model, four methods were used during the calibration and validation periods. The detailed theoretical consideration and formula used is explained here under.

\section{Coefficient of determination $\left(\mathbf{R}^{2}\right)$}

Coefficient of determination is widely used to evaluate the goodness of fit of hydrologic models. The coefficient of determination $\left(\mathrm{R}^{2}\right)$ describes the proportion of the total variance in the observed data that can be explained by the model. It ranges from 0.0 to 1.0 , with higher values indicating better agreement and was calculated by using the following equation;

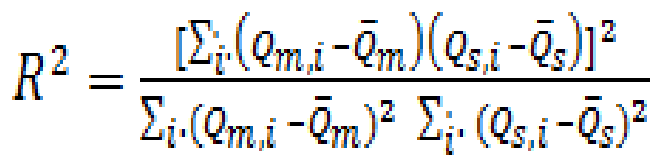

Where, $Q_{m . i}$ is the measured discharge for $i^{\text {th }}$ observed data, $\mathrm{Q}_{\mathrm{s}, \mathrm{i}}$ is the simulated discharge for $\mathrm{i}^{\text {th }}$ simulated value, $\mathrm{Q}_{\mathrm{m}}$ and $\mathrm{Q}_{\mathrm{s}}$ are the average measured and simulated discharge (Leagates and McCabe, 1999).

\section{Nash-Sutcliffe efficiency coefficient (NS)}

The Nash-Sutcliffe efficiency coefficient (Nash and Sutcliffe, 1970) was used to assess the predictive power of the hydrological models. The value of NS varies from one to infinity. An efficiency of lower than zero indicates that the mean value of the observed time series would have been a better predictor than the model. The NS value of 0.0 indicates that the model predictions are as accurate as the mean of the observed data. The NashSutcliffe efficiency (NS) was calculated by using following equation;

$N S E=1-\frac{\sum_{i=1}^{n}\left(Q_{i}-Q_{i}^{\prime}\right)^{2}}{\sum_{i=1}^{n}\left(Q_{i}-Q\right)^{2}}$

Where,

$\mathrm{N}_{\mathrm{SE}}=$ Nash-Sutcliffe coefficient

$\mathrm{Q}_{\mathrm{o}}=$ Observed discharge, $\mathrm{m}^{3} \cdot \mathrm{s}^{-1}$

$\mathrm{Q}_{\mathrm{m}}=$ modeled discharge, $\mathrm{m}^{3} \cdot \mathrm{s}^{-1}$

$\mathrm{Q}_{\mathrm{o}}=$ mean observed discharge, $\mathrm{m}^{3} \cdot \mathrm{s}^{-1}$

$\mathrm{Q}_{\mathrm{t}}=$ discharge at time $\mathrm{t}, \mathrm{m}^{3} \cdot \mathrm{s}^{-1}$

\section{Percent bias (PBIAS)}

Percent bias measures the average tendency of the simulated data to be larger or smaller than their observed value. The optimal value of PBIAS is 0.0 , with low magnitude values indicating accurate model simulation. Positive value indicates model underestimation bias, and negative values indicate model overestimation bias (Moriasi et al., 2007). The PBIAS value was computed by using the following formula;

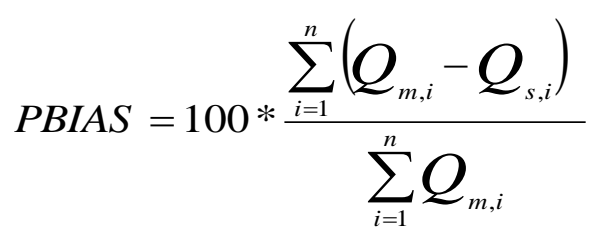

Where, $\mathrm{Q}_{\mathrm{m}, \mathrm{i}}$ and $\mathrm{Q}_{\mathrm{s}, \mathrm{i}}$ are the measured and simulated discharge 
Root mean square error observation standarad deviation ratio (RSR)

The RSR is the root mean square error (RMSE)-observations standard deviation ratio. The RSR was calculated as the ratio of the RMSE and standard deviation of measured data. This performance rating statistics was used in the present study and was caluclated by using the following formula;

$$
R S R=\frac{\sqrt{\sum_{i=1}^{n}\left(Q_{m, i}-Q_{s, i}\right)^{2}}}{\sqrt{\sum_{i=1}^{n}\left(Q_{m, i}-Q_{m}\right)^{2}}}
$$

The criteria for performance rating of hydrological models are given in Table 2.

\section{Results and Discussion}

\section{Sensitivity analysis for stream flow Parameters using SUFI-2}

Global sensitivity analysis method (Abbas et al., 2016) was used for the micro-watershed using 23 hydrological parameters responsible for stream flow. The upper and lower bound parameter values were taken from the QSWAT user manual (Neitsch et al., 2005). Out of 23 parameters (Table 3), 13 were considered for the model calibration. The remaining parameters caused no significant changes in the output results and were not considered in the auto-calibration procedure. Out of these thirteen parameters, the first five were ranked among the top 10 .

Table 4 and Figure 4 shows the global sensitivity analysis for stream flow parameters in Patapur micro-watershed. According to the results obtained from the global sensitivity analysis, the curve number had a larger absolute value for $\mathrm{t}$-stat $(\mathrm{t}=-7.22)$ and simultaneously had minimum absolute value for $p$ value $(p=0.00)$ and hence it is considered as the most sensitive parameter followed by channel hydraulic conductivity $(\mathrm{t}=5.32$, $\mathrm{p}=0.00)$, soil available water content $(\mathrm{t}=1.62$, $\mathrm{p}=0.10)$, groundwater delay $(\mathrm{t}=-1.19, \mathrm{p}=0.23)$, soil evaporation compensation factor $(\mathrm{t}=-1.04$, $\mathrm{p}=0.29)$ and surface runoff lag time $(\mathrm{t}=-0.96$, $\mathrm{p}=0.33$ ) ranking up to sixth position.

\section{Model calibration and Validation}

The parameters analyzed during the sensitivity analysis were also used during the autocalibration procedure. In the SUFI-2 algorithm, 500 simulations were performed in each iteration. The same simulation numbers were used in the validation. The model was run for a period of 5 years (2009-2016) by considering the first 3 years as warm up time of the model. The period 2012-2014 was used for calibration, whereas the remaining 2 years of the dataset, i.e., 2015-2016, were employed for validating the model. The changes to the parameter values obtained from the calibration process are listed in Table 4.

The calibrated $\mathrm{CN}$ value of 82.57 (weighted mean) simulated the runoff which was in close agreement with the observed runoff. The model uses this calibrated $\mathrm{CN}$ values for each sub-watershed and HRUs. The calibration results justify why curve number has the primary control over the abstraction of runoff and deciding the quantity of runoff as $\mathrm{CN}$ value is a function of soil permeability, AMC and land use of the watershed.

The results from this study indicated that the value of $\mathrm{CN}$ can be estimated without much difficulty during calibration. The $\mathrm{CN}$ has been reported to be a significant driver of SWAT model for runoff calibration which is also reported by many researchers (Arnold et al., 2000; White and Chaubey, 2005; Arabi et al., 2008; Yang et al., 2008) 
Table.1 Erodibility factor of soils for layer - I of Patapur micro watershed

\begin{tabular}{|c|c|c|c|c|c|c|c|c|c|c|}
\hline $\begin{array}{l}\text { Sl. } \\
\text { No. }\end{array}$ & $\begin{array}{c}\text { Profile } \\
\text { code }\end{array}$ & Soil mapping unit & $\begin{array}{l}\% \text { Course } \\
\text { Sand }\end{array}$ & $\begin{array}{l}\% \text { Silt }+\% \\
\text { VFS }\end{array}$ & OM & Structure & $\begin{array}{c}\text { Structure } \\
\text { code }\end{array}$ & Permeability & $\begin{array}{l}\text { Permeability } \\
\text { code }\end{array}$ & Soil erodibility \\
\hline 1 & NP1a & PTR1hF3g2R2 & 38.20 & 18.50 & 0.31 & Subangular blocky & 4 & Moderate & 3 & 0.27 \\
\hline 2 & NP1b & PTR 1hF3g2R2 & 30.30 & 18.85 & 0.31 & Subangular blocky & 4 & Moderate & 3 & 0.27 \\
\hline 3 & NP2 & PTR3hD3 & 42.50 & 50.90 & 1.34 & Subangular blocky & 4 & Rapid & 1 & 0.22 \\
\hline 4 & NP3a & PTR3cC3 & 35.70 & 13.40 & 1.25 & Subangular blocky & 4 & Moderate & 3 & 0.25 \\
\hline 5 & NP3b & PTR3hC2 & 36.50 & 14.90 & 1.17 & Subangular blocky & 4 & Moderate & 3 & 0.26 \\
\hline 6 & NP4 & PTR 1hE3g2R2 & 45.60 & 54.80 & 1.17 & Subangular blocky & 4 & Rapid & 1 & 0.23 \\
\hline 7 & NP5a & PTR 3cD3g2R2 & 40.20 & 44.70 & 1.18 & Subangular blocky & 4 & Rapid & 1 & 0.22 \\
\hline 8 & NP5b & PTR3cD3 & 40.00 & 42.58 & 1.18 & Subangular blocky & 4 & Rapid & 1 & 0.22 \\
\hline 9 & NP5c & PTR3cD3 & 41.50 & 44.40 & 1.19 & Subangular blocky & 4 & Rapid & 1 & 0.22 \\
\hline 10 & NP5d & PTR2cD3 & 23.45 & 25.83 & 1.69 & Subangular blocky & 4 & Slow & 5 & 0.30 \\
\hline 11 & NP6 & PTR3mB2 & 34.40 & 13.60 & 1.34 & Subangular blocky & 4 & Moderate & 3 & 0.25 \\
\hline 12 & NP7a & PTR2hD3g2R2 & 32.50 & 11.70 & 1.06 & Subangular blocky & 4 & Moderate & 3 & 0.26 \\
\hline 13 & NP7b & PTR1hE3g2R2 & 30.20 & 14.30 & 0.98 & Subangular blocky & 4 & Rapid & 1 & 0.21 \\
\hline 4 & $\mathrm{NP7c}$ & PTR1cD3g2R2 & 74.80 & 85.00 & 1.17 & Subangular blocky & 4 & Rapid & 1 & 0.25 \\
\hline 15 & NP8 & PTR1cF3R4 & 75.20 & 81.20 & 0.45 & Subangular blocky & 4 & Rapid & 1 & 0.25 \\
\hline 16 & OP2a & PTR6cC2 & 74.80 & 81.00 & 0.56 & Subangular blocky & 4 & Rapid & 1 & 0.25 \\
\hline 17 & $\mathrm{OP} 2 \mathrm{~b}$ & PTR5cD3 & 18.20 & 25.90 & 0.53 & Subangular blocky & 4 & Slow & 5 & 0.31 \\
\hline 18 & OP3a & PTR5mC2 & 44.80 & 54.00 & 0.61 & Subangular blocky & 4 & Rapid & 1 & 0.23 \\
\hline 19 & OP3b & PTR3cD3 & 41.20 & 42.80 & 0.67 & Subangular blocky & 4 & Rapid & 1 & 0.23 \\
\hline 20 & $\mathrm{OP} 3 \mathrm{c}$ & PTR3cD3g2S1 & 38.00 & 25.60 & 0.73 & Subangular blocky & 4 & Moderate & 3 & 0.27 \\
\hline 21 & OP4 & PTR6hB2g2s1 & 29.00 & 10.40 & 0.61 & Subangular blocky & 4 & Moderate & 3 & 0.26 \\
\hline 22 & OP5a & PTR5hC2 & 29.00 & 10.40 & 0.73 & Subangular blocky & 4 & Moderate & 3 & 0.26 \\
\hline 23 & OP5b & PTR5hD3 & 9.50 & 19.80 & 0.61 & Subangular blocky & 4 & Slow & 5 & 0.31 \\
\hline 24 & OP6 & PTR5mB2 & 38.20 & 28.10 & 0.69 & Subangular blocky & 4 & Moderate & 3 & 0.27 \\
\hline
\end{tabular}

Table.5 Calibration and validation statistics for stream flow discharge and sediment yield for Patapur micro-watershed

\begin{tabular}{|c|c|c|c|c|c|c|c|c|c|c|c|c|}
\hline Parameters $\longrightarrow$ & p-factor & r-factor & $\mathbf{R}^{2}$ & NS & PBIAS & RSR & p-factor & r-factor & $\mathbf{R}^{2}$ & NS & PBIAS & RSR \\
\hline Time step $\downarrow$ & \multicolumn{6}{|c|}{ Discharge calibration (2012-2014) } & \multicolumn{6}{|c|}{ Discharge validation (2015-2016) } \\
\hline Daily & 0.07 & 0.07 & 0.88 & 0.87 & 21.30 & 0.36 & 0.85 & 0.05 & 0.63 & 0.64 & 24.00 & 0.56 \\
\hline Monthly & 0.11 & 0.33 & 0.72 & 0.72 & -14.00 & 0.53 & 0.17 & 0.24 & 0.50 & 0.55 & 22.50 & 0.70 \\
\hline Annual & 1.00 & 0.00 & 0.81 & 0.88 & 1.30 & 0.35 & 1.00 & 0.00 & 0.92 & 0.54 & -23.00 & 0.67 \\
\hline
\end{tabular}


Int.J.Curr.Microbiol.App.Sci (2018) 7(4): 831-852

Table.2 Performance ratings of hydrologic model

\begin{tabular}{|c|c|c|c|c|c|c|}
\hline SI. & Performance & RSR & NSE & \multicolumn{2}{|c|}{ PBIAS } & \multirow[t]{2}{*}{$\mathbf{R}^{2}$} \\
\hline & & & & Stream flow & Sediment & \\
\hline 1 & Very Good & $0.00 \leq \mathrm{RSR} \leq 0.50$ & $0.75<\mathrm{NSE} \leq 1.0$ & PBIAS $\leq \pm 10$ & PBIAS $\leq \pm 15$ & $0.7-1.0$ \\
\hline 2 & Good & $0.50 \leq \mathrm{RSR} \leq 0.60$ & $\begin{array}{l}0.65<\mathrm{NSE} \leq \\
0.75\end{array}$ & $\pm 10 \leq$ PBIAS $\leq \pm 15$ & $\begin{array}{l} \pm 15 \leq \text { PBIAS } \leq \pm \\
30\end{array}$ & $0.6-0.70$ \\
\hline 3 & Satisfactory & $0.60 \leq \mathrm{RSR} \leq 0.70$ & $\begin{array}{l}0.50 \leq \mathrm{NSE} \\
0.65\end{array}$ & $\pm \leq$ PBIAS $\leq \pm 25$ & $\begin{array}{l} \pm 30 \leq \text { PBIAS } \leq \pm \\
55\end{array}$ & $0.5-0.6$ \\
\hline 4 & Unsatisfactory & $\mathrm{RSR}>0.70$ & $\mathrm{NSE} \leq 0.50$ & PBIAS $\geq \pm 25$ & PBIAS $\geq \pm 55$ & $<0.5$ \\
\hline
\end{tabular}

Table.3 Global sensitivity analysis for stream flow parameters in Patapur micro-watershed

\begin{tabular}{|c|l|c|c|c|}
\hline Sl. No. & \multicolumn{1}{|c|}{ Parameter Name } & Sensitivity rank & t-Stat & p-Value \\
\hline $\mathbf{1}$ & R_CN2.mgt & 1 & -7.22 & 0.00 \\
\hline $\mathbf{2}$ & R_CH_K2.rte & 2 & 5.32 & 0.00 \\
\hline $\mathbf{3}$ & R_SOL_AWC.sol & 3 & 1.62 & 0.10 \\
\hline $\mathbf{4}$ & V_GW_DELAY.gw & 4 & -1.19 & 0.23 \\
\hline $\mathbf{5}$ & R_ESCO.hru & 5 & -1.04 & 0.29 \\
\hline $\mathbf{6}$ & R_SURLAG.bsn & 6 & -0.96 & 0.33 \\
\hline $\mathbf{7}$ & V_GW_REVAP.gw & 7 & -0.91 & 0.36 \\
\hline $\mathbf{8}$ & V_REVAPMN.gw & 8 & -0.90 & 0.37 \\
\hline $\mathbf{9}$ & V_ALPHA_BF.gw & 9 & 0.77 & 0.44 \\
\hline $\mathbf{1 0}$ & V_GWQMN.gw & 1 & 0.64 & 0.51 \\
\hline $\mathbf{1 1}$ & R_SOL_K.sol & 11 & 0.48 & 0.63 \\
\hline $\mathbf{1 2}$ & V_EPCO.hru & 12 & -0.47 & 0.64 \\
\hline $\mathbf{1 3}$ & V_HRU_SLP.hru & 13 & 0.02 & 0.98 \\
\hline
\end{tabular}

Table.4 Daily stream flow calibration fitted values for Patapur micro-watershed (2012-2014)

\begin{tabular}{|c|l|c|c|c|}
\hline Sl. No. & \multicolumn{1}{|c|}{ Parameter Name } & Fitted value & Min value & Max value \\
\hline $\mathbf{1}$ & R_CN2.mgt & 0.06 & 0.03 & 0.12 \\
\hline $\mathbf{2}$ & R_CH_K2.rte & 0.09 & 0.00 & 18.93 \\
\hline $\mathbf{3}$ & R_SOL_AWC.sol & 18.37 & 14.79 & 24.59 \\
\hline $\mathbf{4}$ & V_GW_DELAY.gw & 143.71 & 85.26 & 186.91 \\
\hline $\mathbf{5}$ & R_ESCO.HRU & 0.60 & 0.540 & 0.725 \\
\hline $\mathbf{6}$ & R_SURLAG.bsn & 0.85 & 0.57 & 2.34 \\
\hline $\mathbf{7}$ & V_GW_REVAP.gw & 0.03 & 0.03 & 0.03 \\
\hline $\mathbf{8}$ & V_REVAPMN.gw & 468.07 & 452.70 & 586.29 \\
\hline $\mathbf{9}$ & V_ALPHA_BF.gw & 0.47 & 0.39 & 0.53 \\
\hline $\mathbf{1 0}$ & V_GWQMN.gw & 887.70 & 765.00 & 1673.88 \\
\hline $\mathbf{1 1}$ & R_SOL_K.sol & 20.16 & 5.50 & 53.57 \\
\hline $\mathbf{1 2}$ & V_EPCO.hru & 1.10 & 0.89 & 1.32 \\
\hline $\mathbf{1 3}$ & V_HRU_SLP.hru & 0.14 & 0.13 & 0.18 \\
\hline
\end{tabular}


Fig.1 Delineation of soils into mapping units of Patapur watershed

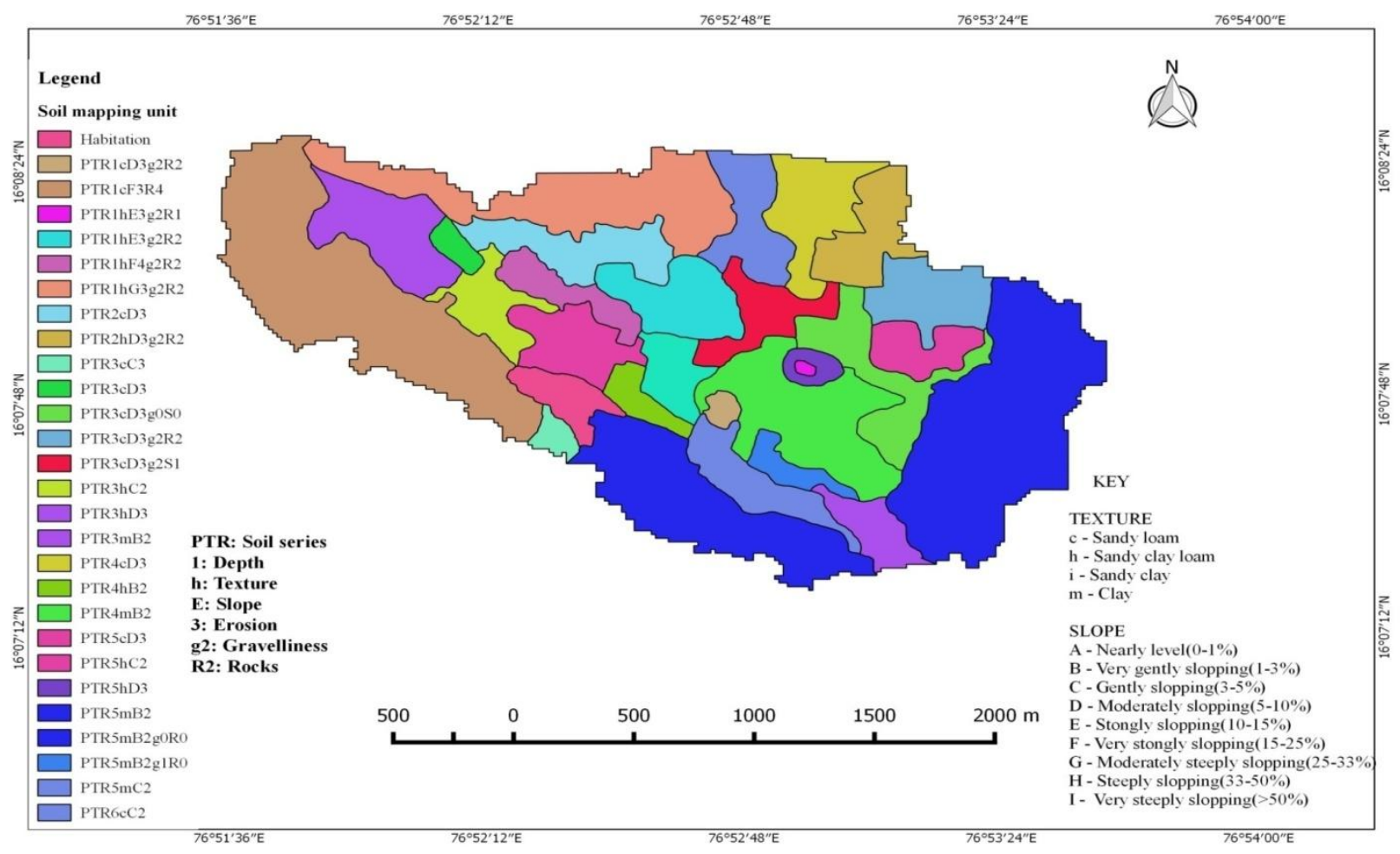

Fig.2a DEM map of Patapur micro-watershed

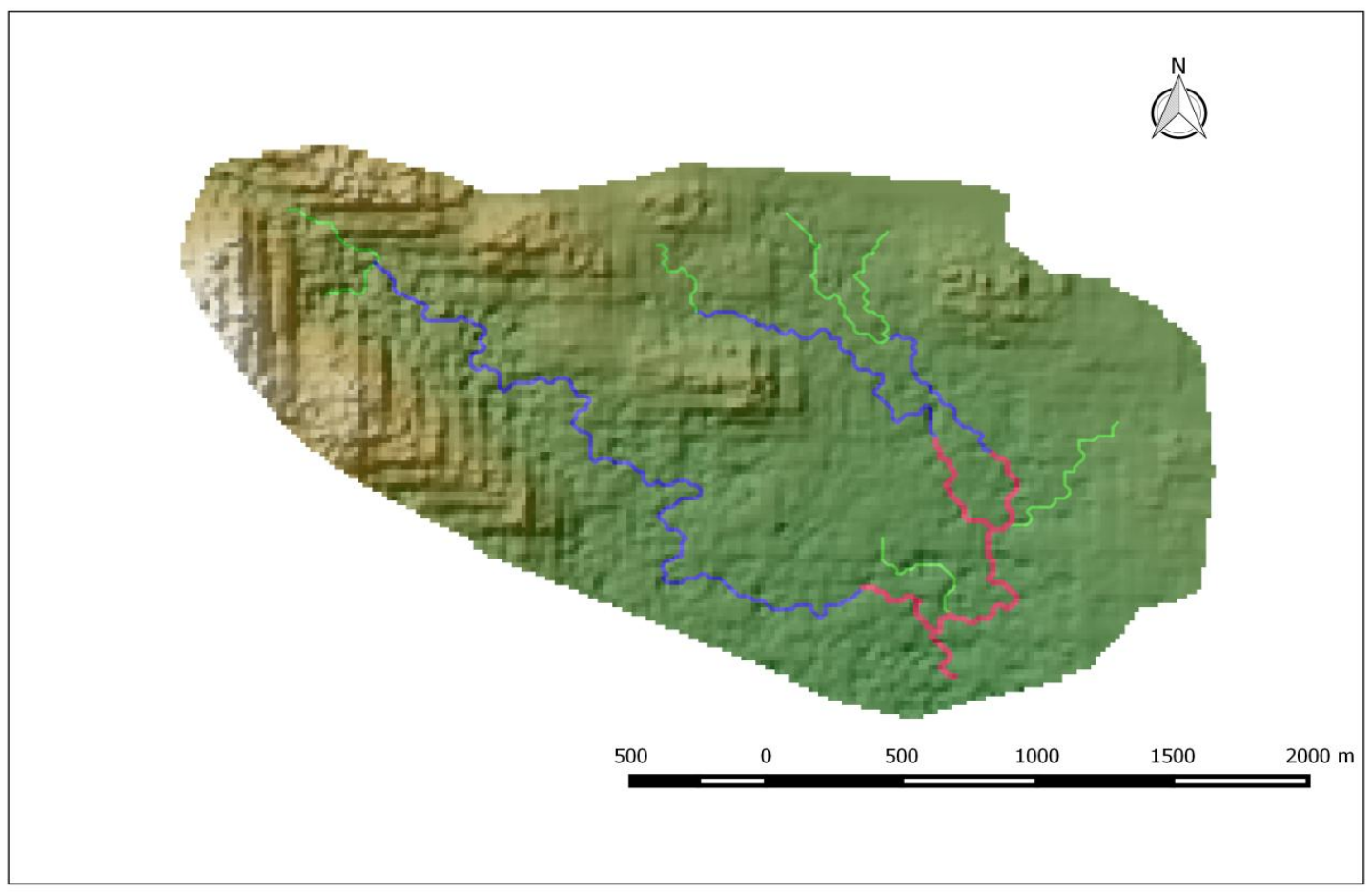


Fig.2b Slope map of Patapur micro-watershed

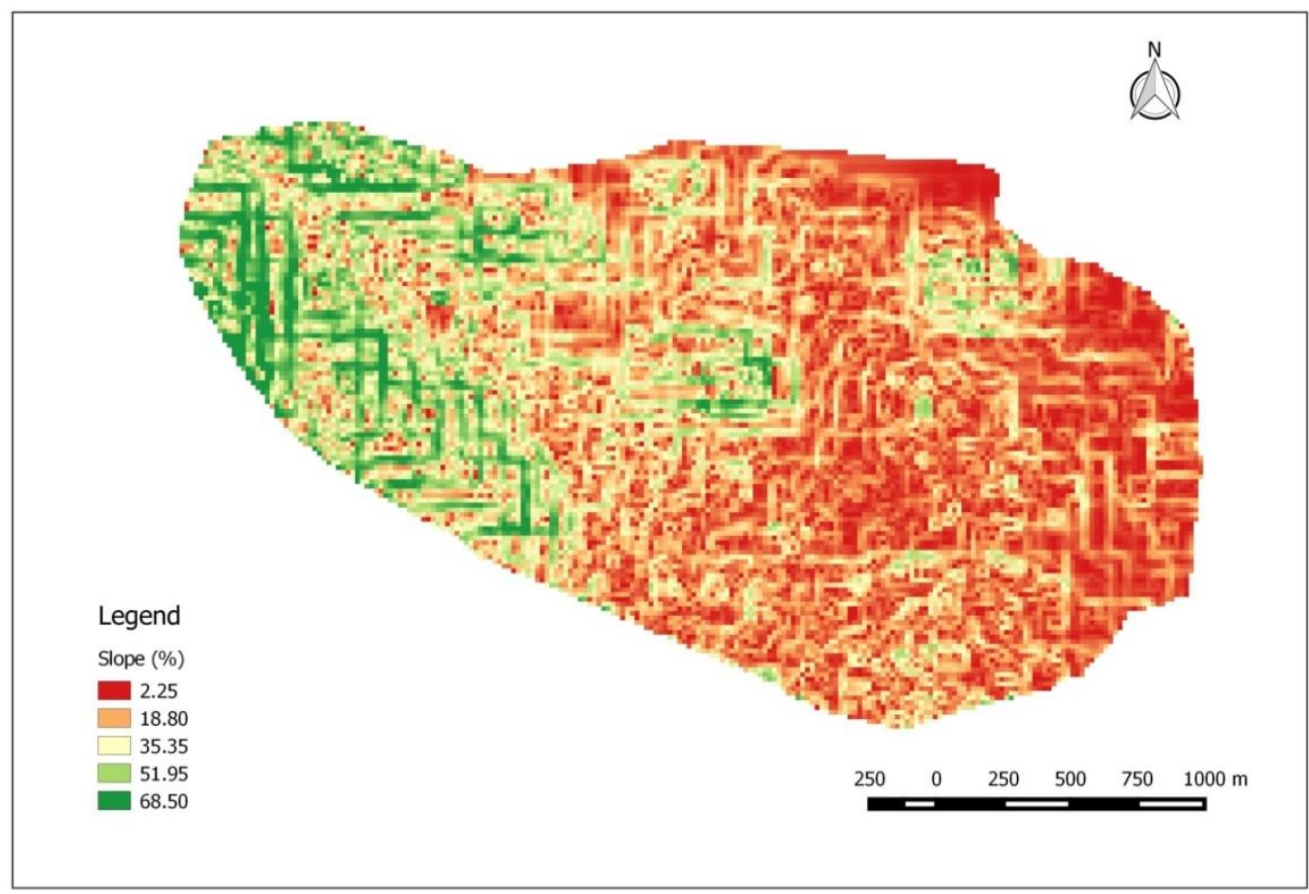

Fig.2c Contour map of Patapur micro-watershed $76^{\circ} 51.6^{\prime} \mathrm{E}$ $76^{\circ} 52.8^{\prime} \mathrm{E}$

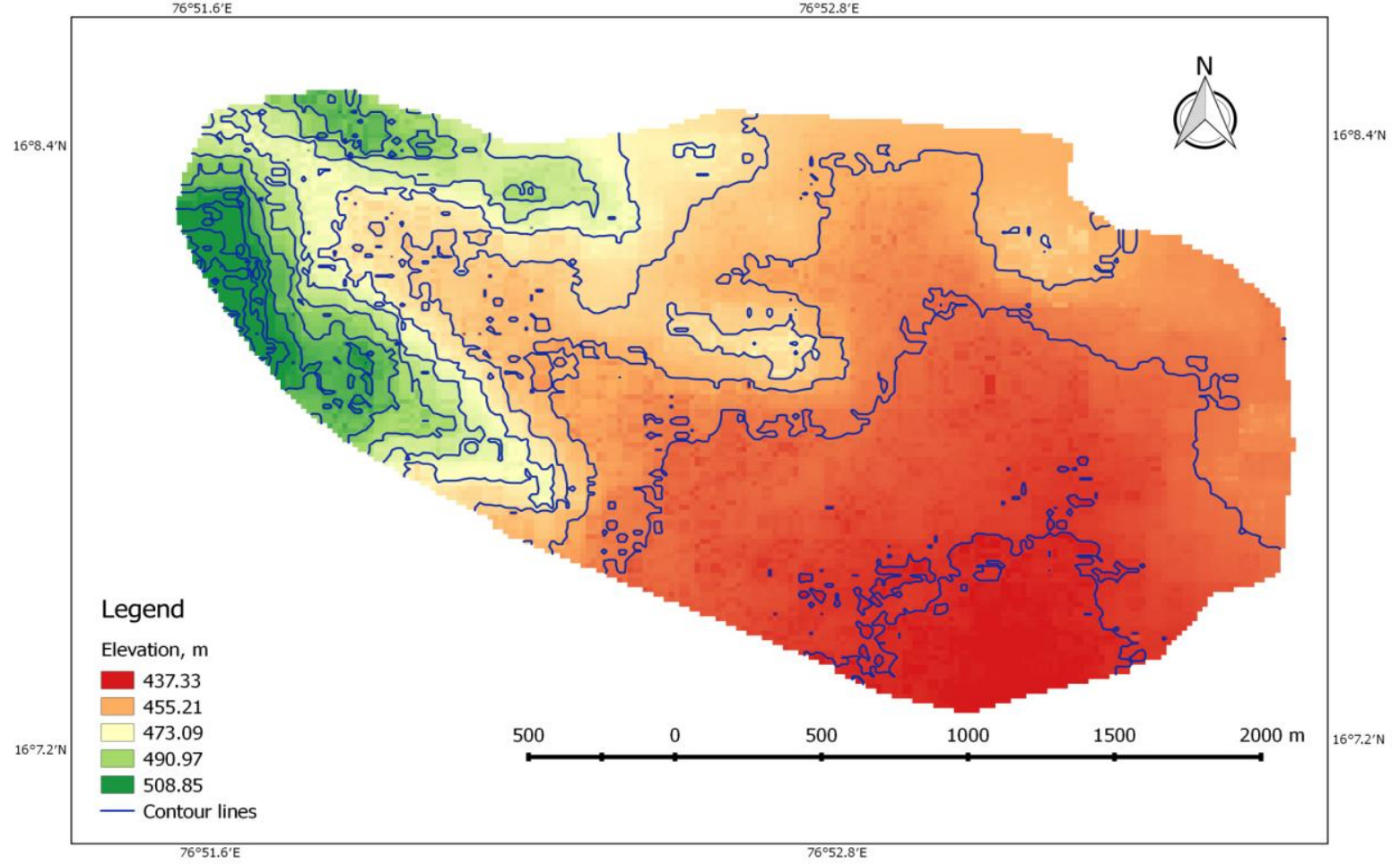


Int.J.Curr.Microbiol.App.Sci (2018) 7(4): 831-852

Fig.2d Relief map of Patapur micro-watershed

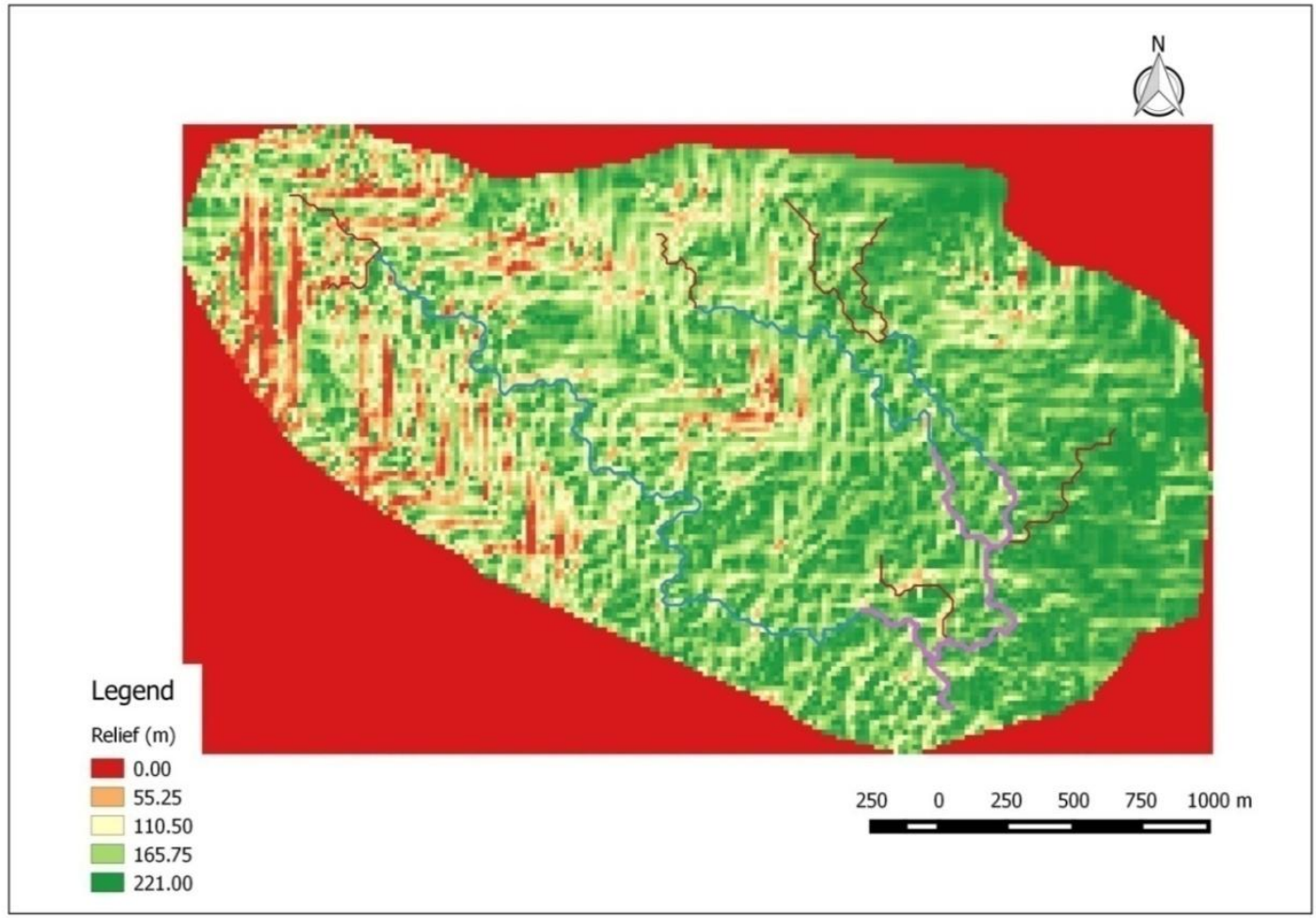

Fig.3 Land use map of Patapur micro-watershed during 2015

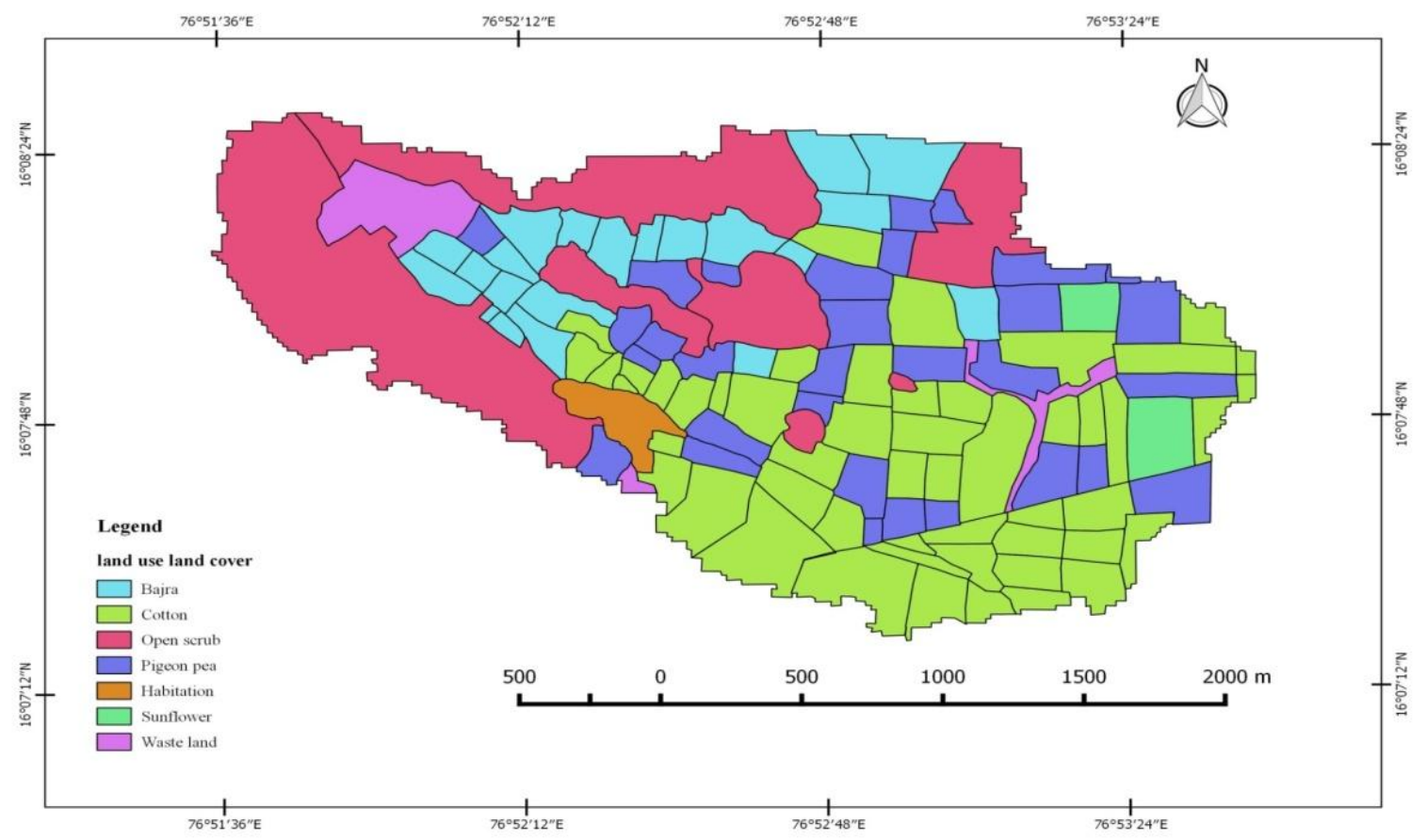


Fig.4 The screen shot image of global sensitivity output for stream flow sensitivity analysis showing the rank of hydrological parameter from bottom up

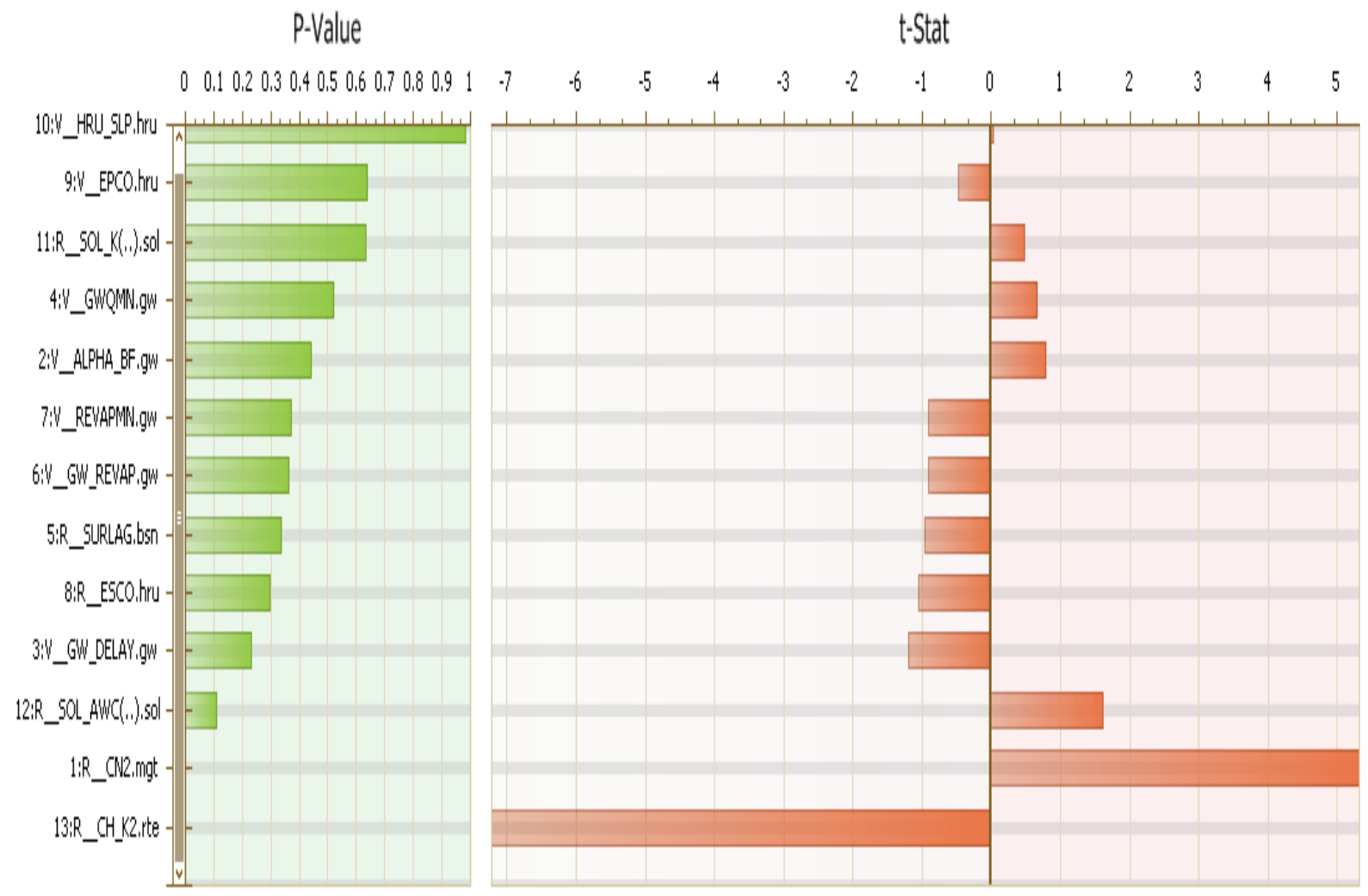

Fig.5 Comparison between daily simulated and observed stream flow for calibration period (2012-2014)

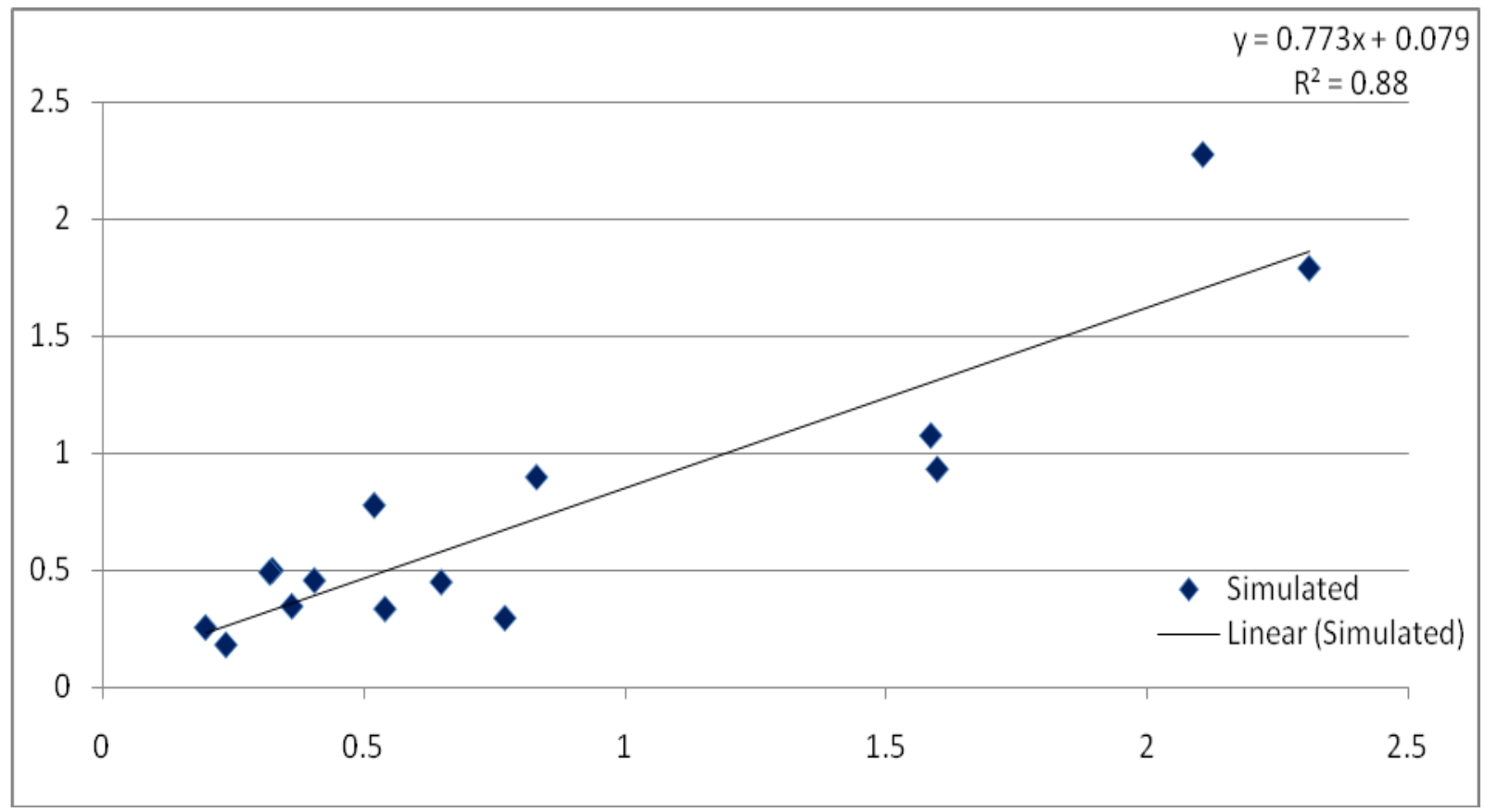


Fig.6 Simulated vs. observed average daily discharge at the watershed outlet for calibration (2012-2014)

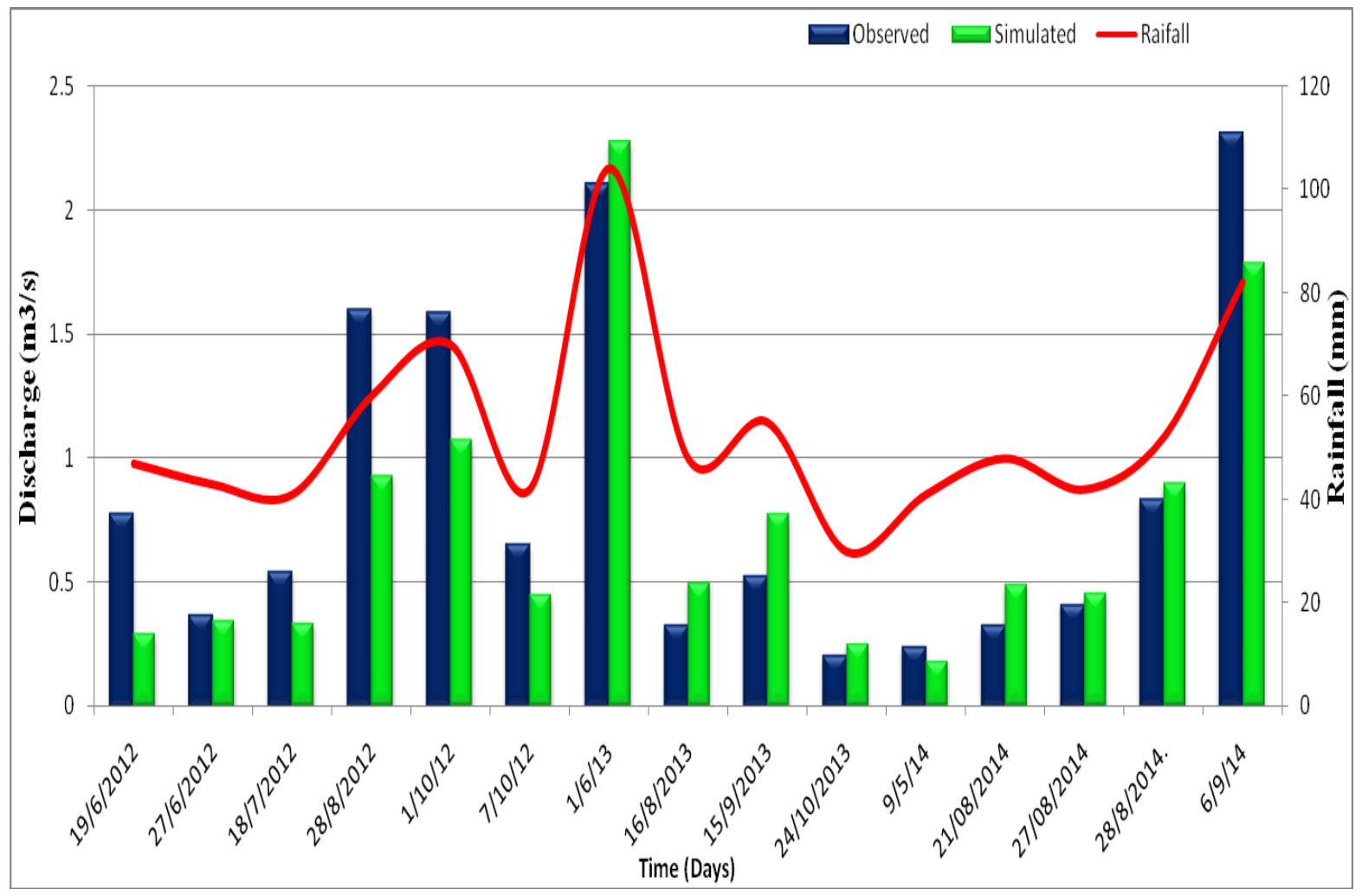

Fig.7 Comparison of Simulated vs. observed average daily discharge at the watershed outlet for validation (2015-2016)

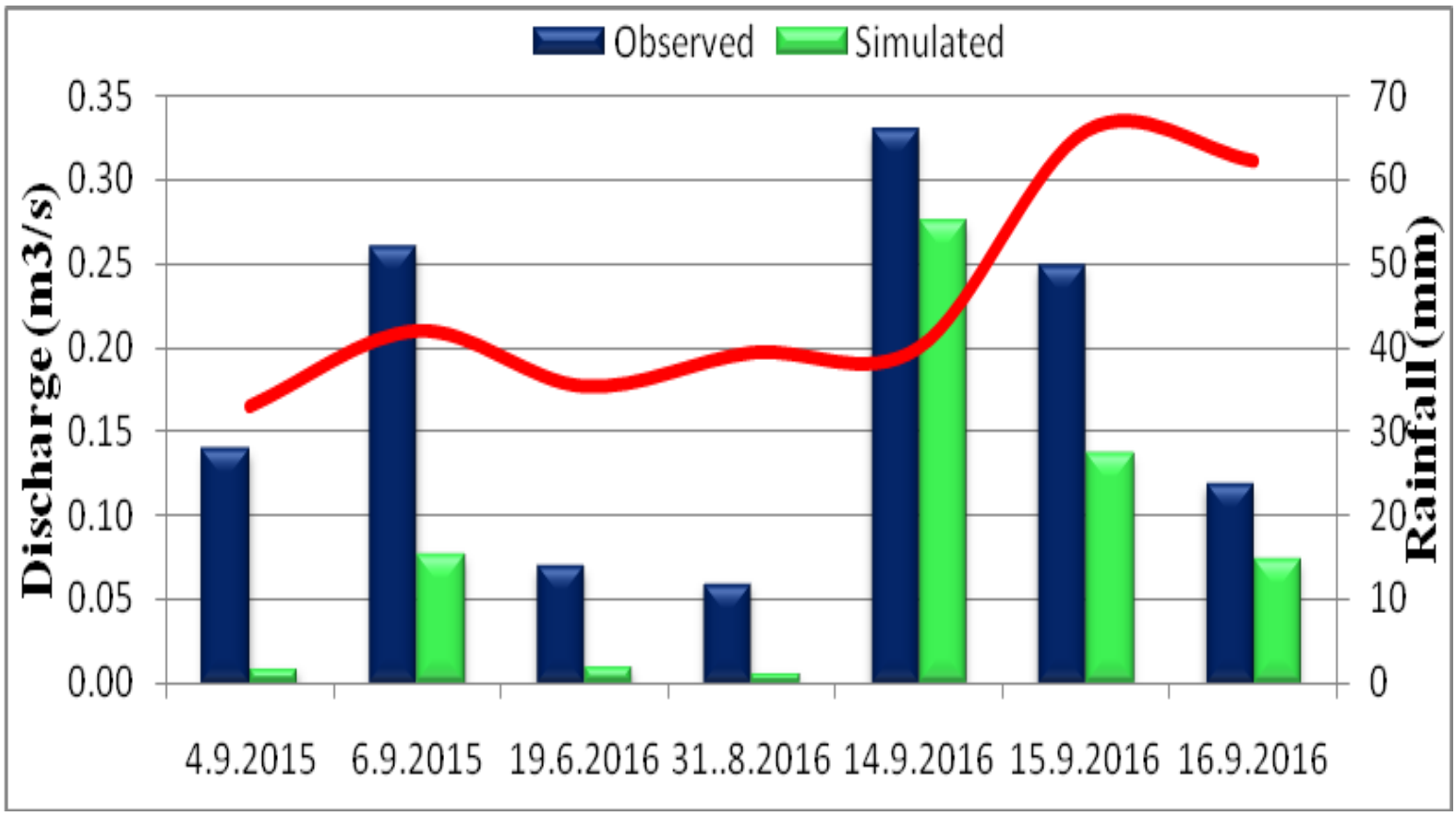


Fig.8 Comparison between daily simulated and observed flow for validation period (2015-2016)

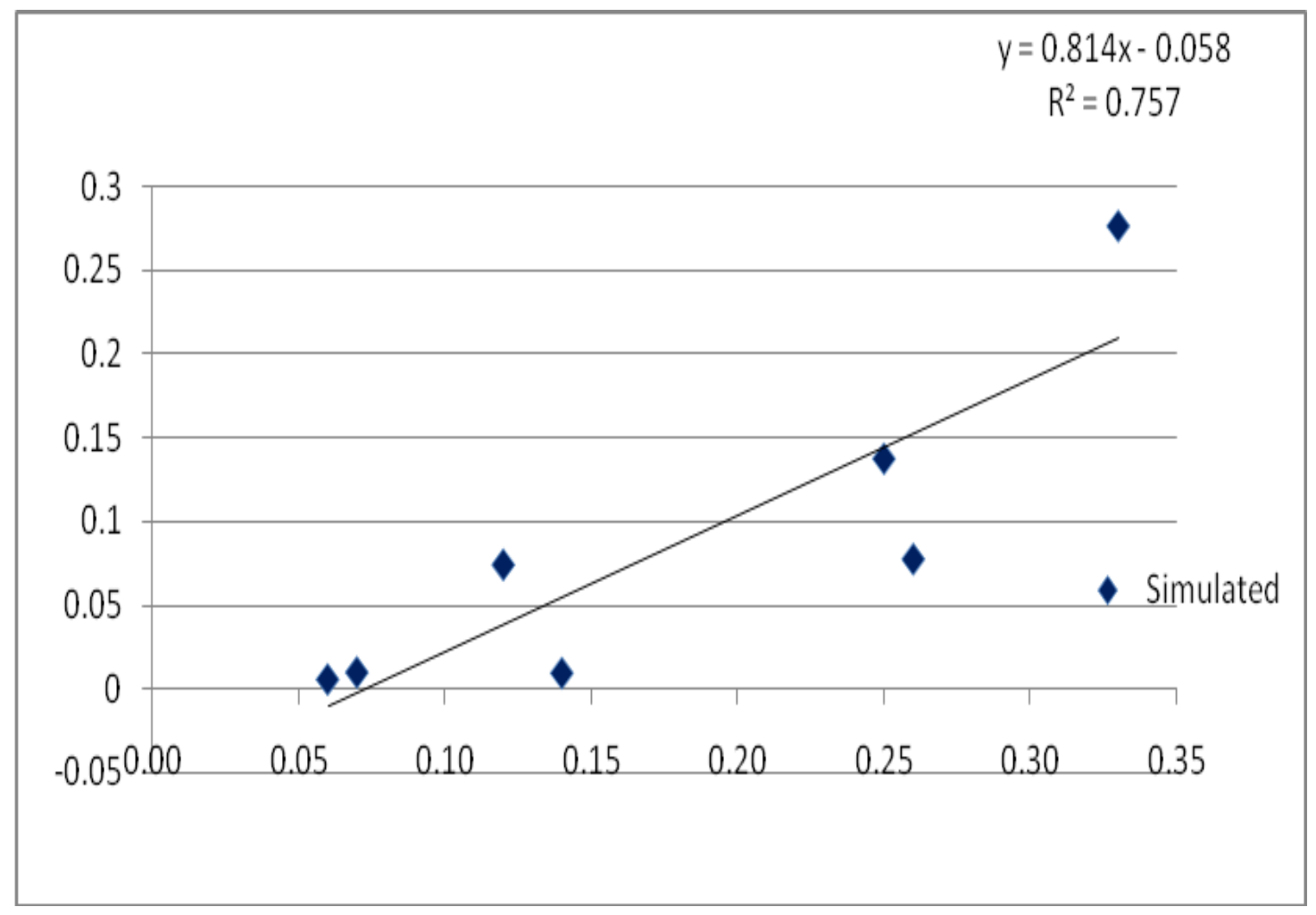

Fig.9 95 PPU plot by SUFI-2 during uncertainty analysis at the outlet of the watershed for daily calibration of stream discharge (2012-2014)

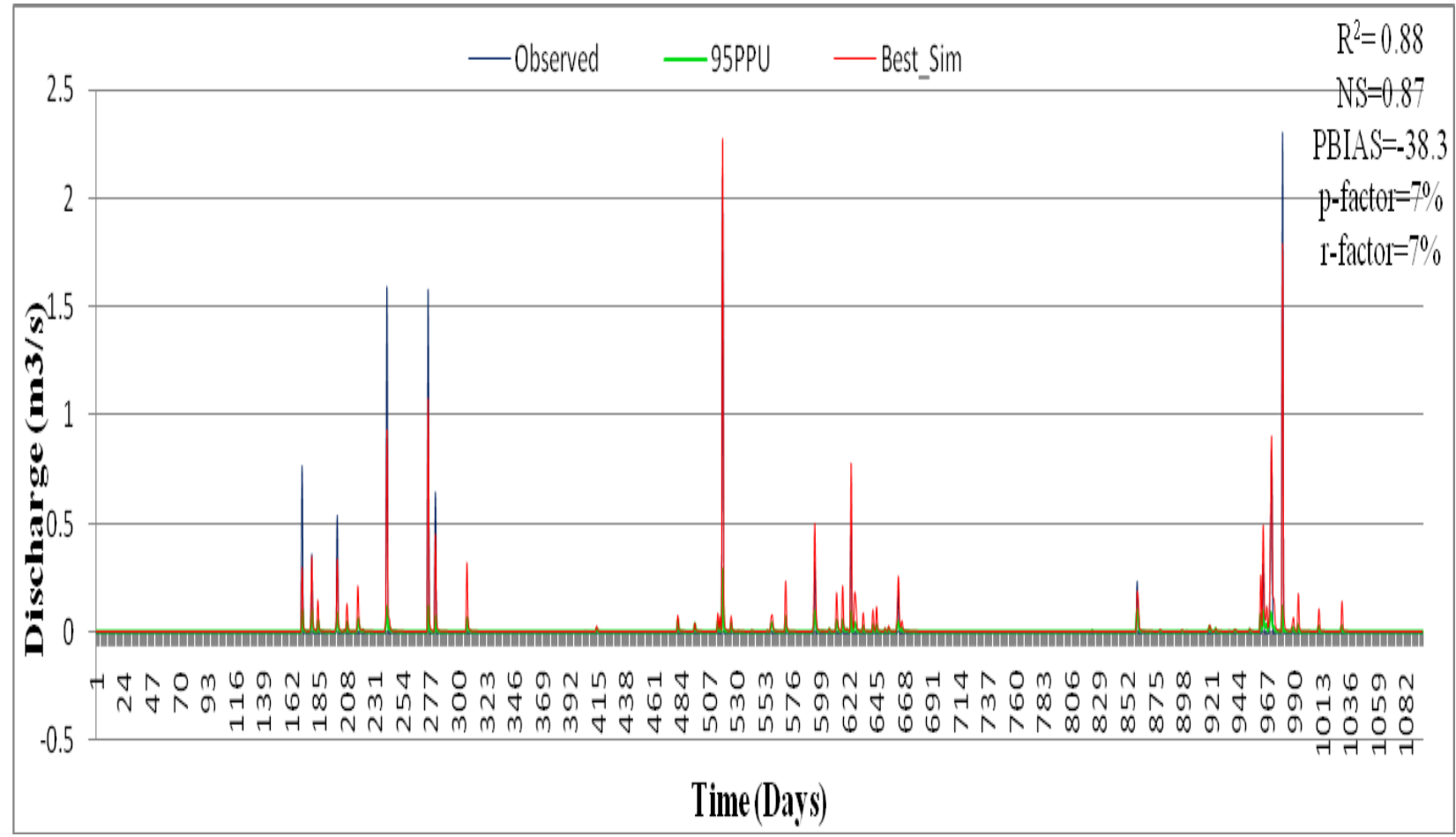


Fig.10 95 PPU plot by SUFI-2 during uncertainty analysis at the outlet of the watershed for daily validation of stream discharge (2015-2016)

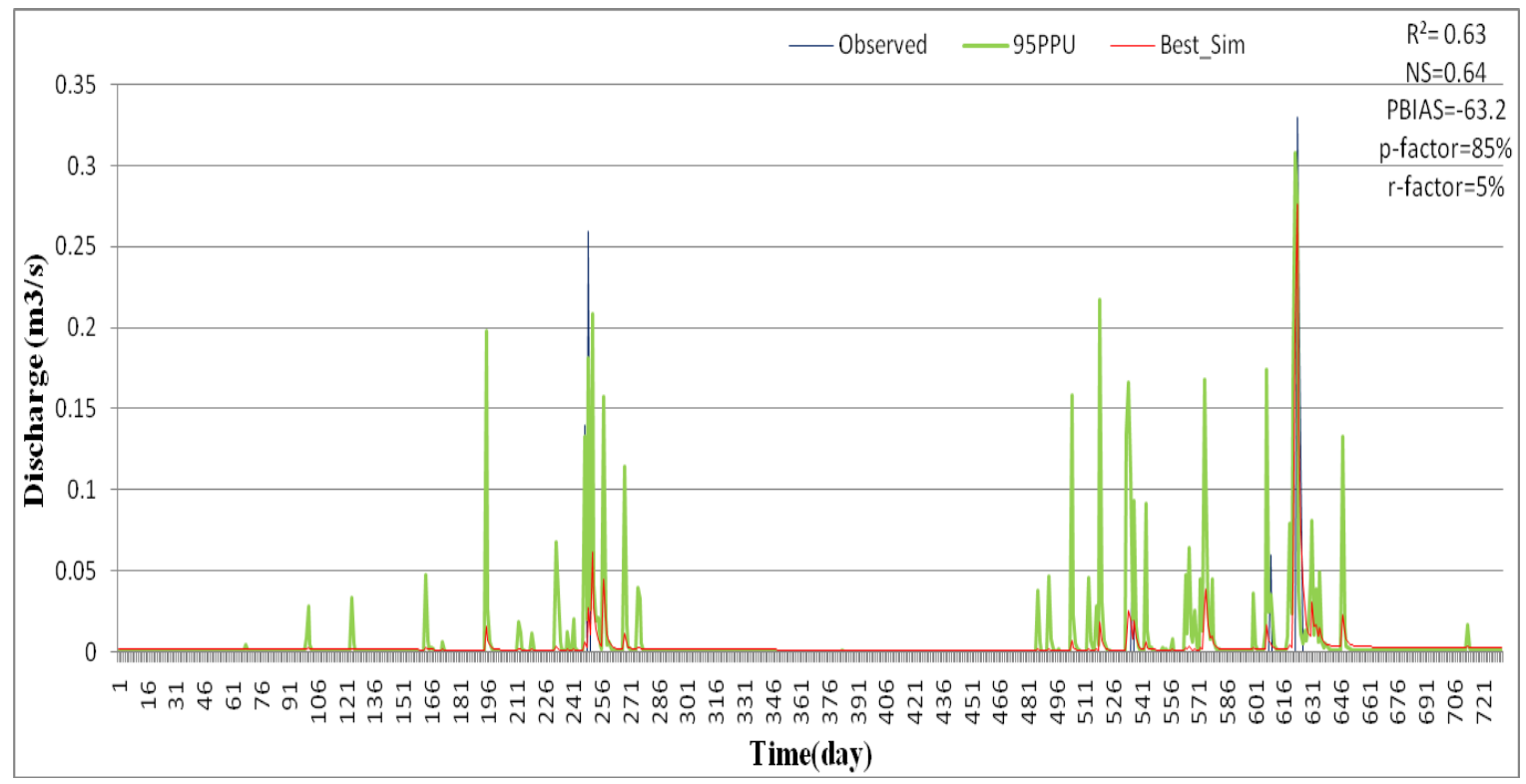

Fig.11 Dot plots depicting NS value against stream flow parameters at final iteration in the validation phase with SUFI2 software of SWAT-CUP model
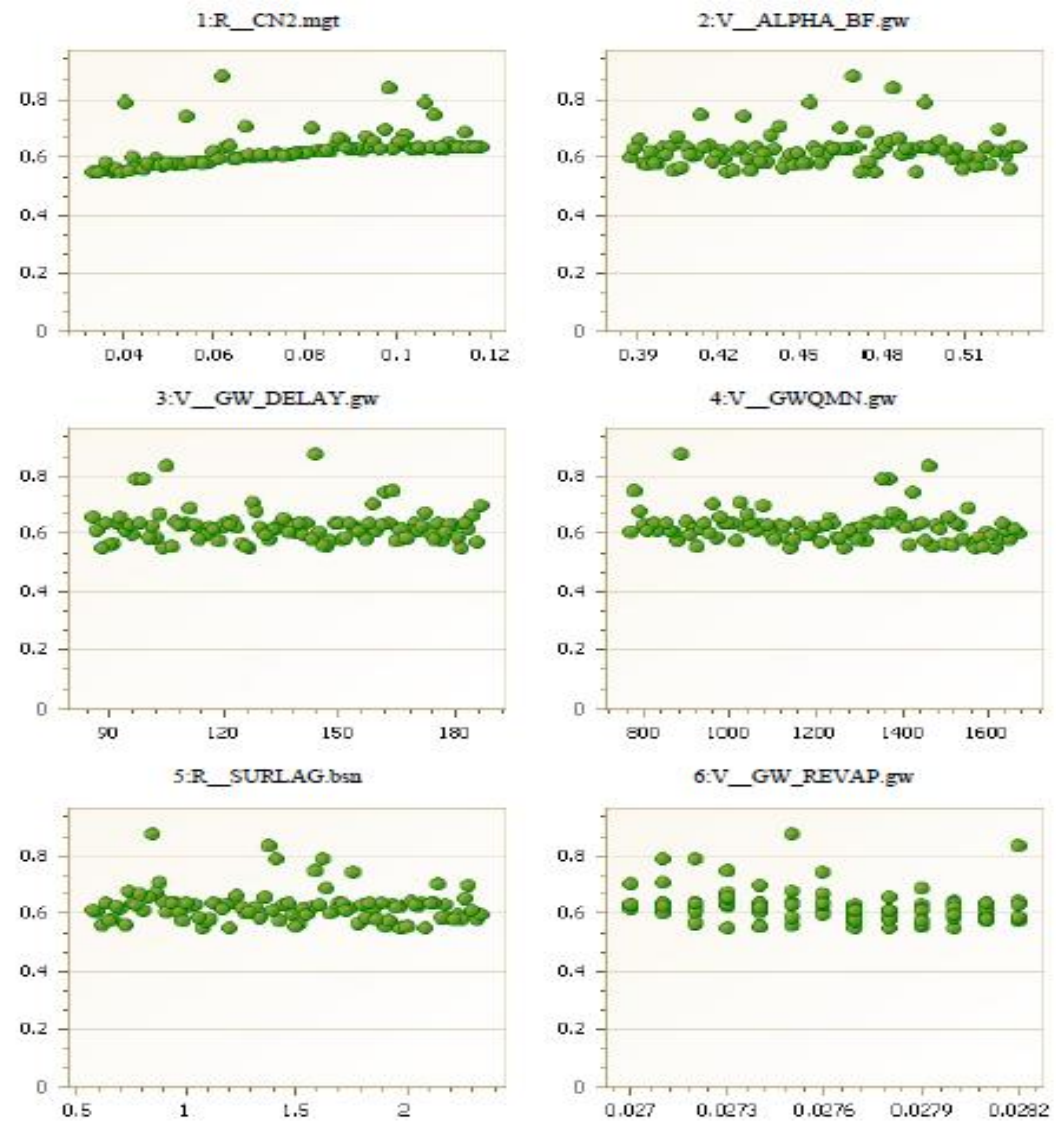

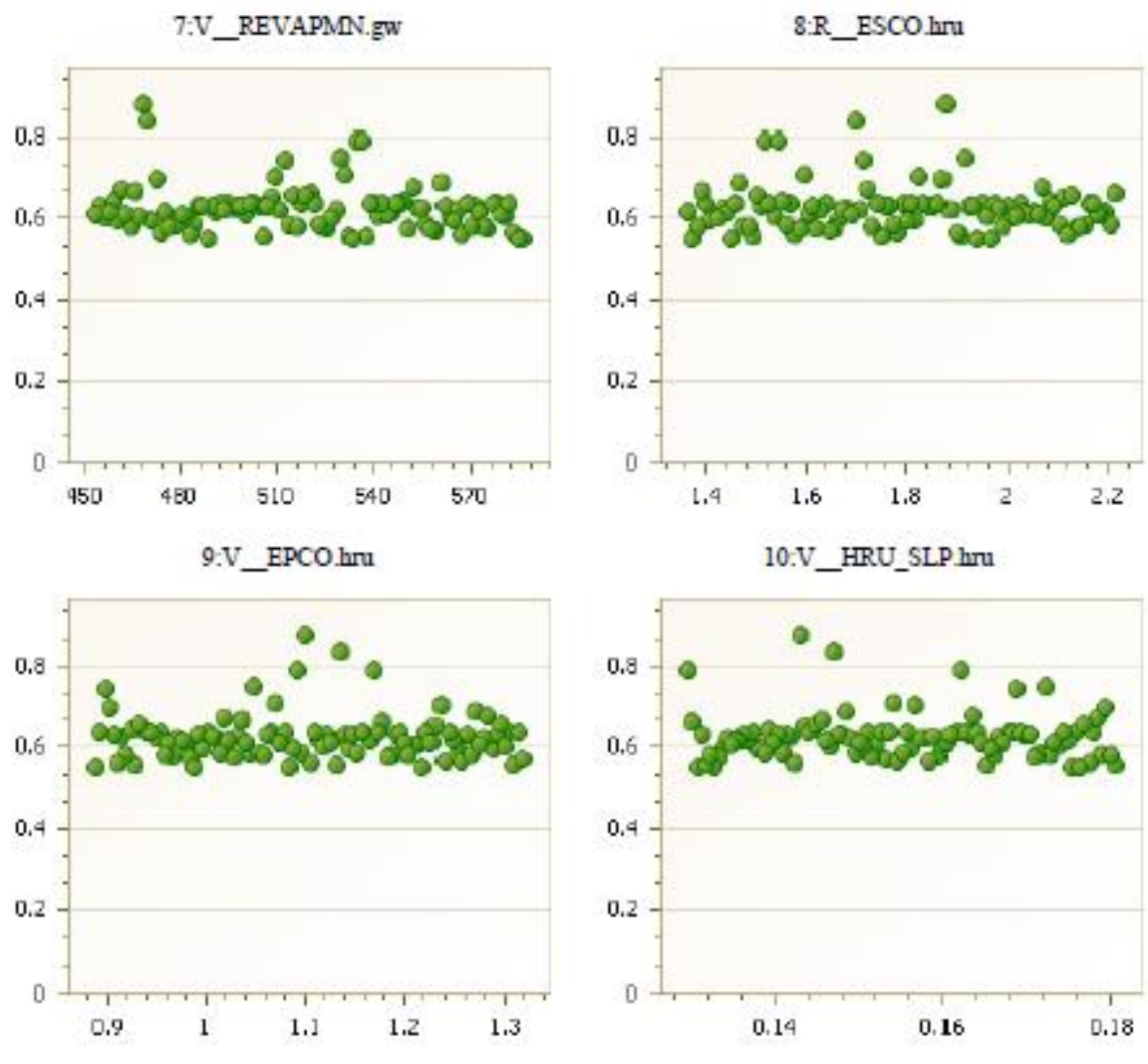

$11: R \_S O L \_K(.)$.

12:R_SOL_AWC(..). sol
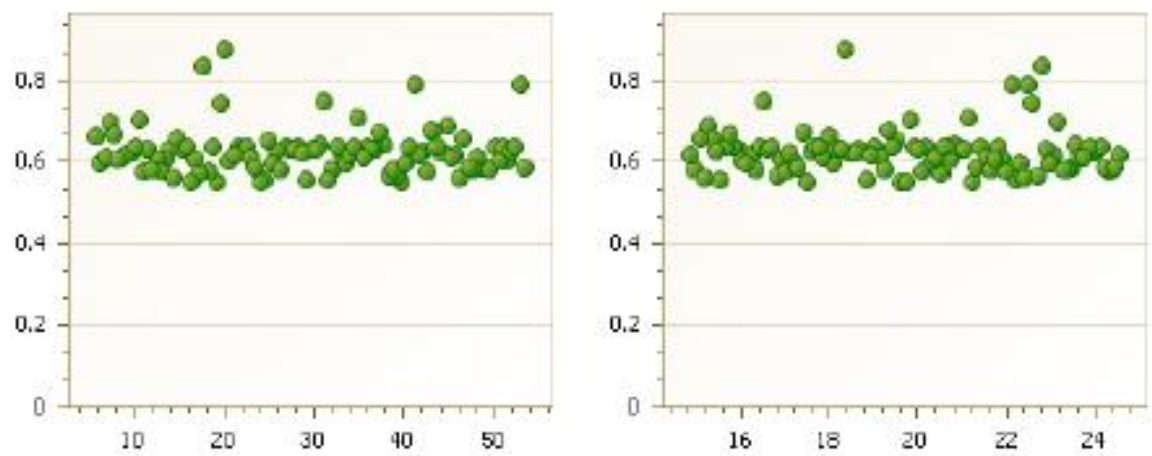

$13: \mathrm{R} \_\mathrm{CH}$ K 2. rte

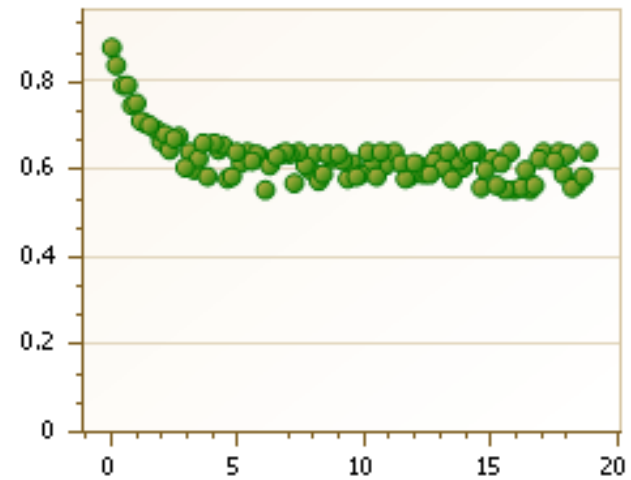


The "soil available water capacity (SOL_AMC)" value was higher for clay as compared to sandy clay loam soils to accumulate more water in the soils thereby increasing the field capacity of soil and decreasing the lateral flow which otherwise would contributed to runoff.

High values of SOL_AWC signify a high capacity of the soil to maintain its water holding capacity, which reduces the amount of water available for surface runoff and percolation and therefore affects the generation of surface runoff. The soil evaporation compensation factor (ESCO) was reduced which resulted into greater evapotranspiration from lower layer and consequently affects the AMC of soil layer which in turn mirrored on reduced runoff, base flow and soil water content. In the present study the reason could be for low calibrated value of ESCO is due to higher temperature in watershed which is characterized by semi-arid regions generally evaporative demand is high. The parameters discussed above would govern the behavior of surface waters and favor the direct contribution of surface runoff to the channel discharge.

The high base flow was also adjusted by increasing the groundwater related parameter namely, threshold depth of water (GWQMN) in shallow aquifer, groundwater revap coefficient was increased and threshold depth of water (REVAPMN) in shallow aquifer was decreased with a reason that there is limited scope for the groundwater recharge as 43.34 per cent of the watershed falls under high slope $(10 \%)$ coupled with 30 per cent open scrub land covering outcrop and hard subsurface soil profile. The similar results were also reported by many researchers (Arnold $e t$ al., 2000; White and Chaubey, 2005; Arabi et al., 2007; Yang et al., 2008; and Muleta et al., 2007).
The calibration and validation statistics are given in the Table 5, which shows the model calibration for the three years 2012-2014 and validation for the two years period 20152016. It is observed from the table that, the calibration statistics $\mathrm{R}^{2}$, NS, PBIAS and RSR values between measured and simulated by model was found to be $0.88,0.87,-21.30$ and 0.36 , respectively indicating the model performance for daily calibration was very good in terms of both $\mathrm{R}^{2}$ and NS value as their value being $>0.75$ as per the performance rating $\mathrm{s}$ of hydrological model. And also, in terms of PBIAS and RSR value the model performance was found to be satisfactory respectively. The negative PBIAS value showed that the model had slightly over predicted the discharge. The Figure 5 shows the goodness of fit and Figure 6 shows the graphical comparison of simulated vs. measured daily discharge. From this figure it was found that the discharge is directly proportional to the rainfall. Further, in the year 2012 and 2014 simulated discharge was less than the observed and in 2013 it was more than the observed. The negative PBIAS value indicated that the model had slightly over predicted the average daily discharge by 24.00 per cent especially during the dry year. The reason for this disparity between measured and predicted values might be due to the inaccurate estimation of hydrological conditions in the soil profile and limited amount of measured data available in the watershed. These findings are in line with Gangaram et al., 2013).

The calibrated model was then run for two years from 2015-2016 to validate the calibrated model. Daily validation statistics results for behavioral parameters in SWATCUP for stream flow discharge during the period 2015-2016 is shown in Table 5. The validation statistics also displayed satisfactory model performance, with $\mathrm{R}^{2}$ NS, PBIAS and RSR values between measured responses and 
values predicted by the calibrated model was found to be $0.63,0.64,-24.00$ and 0.56 respectively indicating the model performance for daily validation good in terms of both $\mathrm{R}^{2}$ and NS values. However, with respect to PBIAS and RSR values the model performance was found to be satisfactory and good respectively. The negative PBIAS value indicated that the model had over predicted the daily average discharge. It was also noted that the model did not perform well during the year 2015-2016 (lower performance and larger uncertainty). As shown in Figure 7 it is observed that in all the runoff events, the observed discharge was more than simulated. The highest daily average discharge of 0.326 and $0.276 \mathrm{~m}^{3} \mathrm{sec}^{-1}$ for observed and simulated flow respectively, followed by $0.26 \mathrm{~m}^{3} \mathrm{sec}^{-1}$ (observed) and $0.137 \mathrm{~m}^{3} \mathrm{sec}^{-1}$ (simulated). The plot of the observed versus simulated discharge showing the goodness of fit is shown in Figure 8 and found that the observed and simulated daily discharge reasonably matched.

\section{Uncertainty analysis of runoff modeling}

The uncertainty analysis with SUFI-2 for both the calibration and validation periods are shown in Figures 9 and 10. The results had shown that p-factor for daily, monthly and annual time step were 0.07 (7\%), 0.11(11\%), $1.0(100 \%)$, respectively while $\mathrm{r}$-factor for daily, monthly and annual were 0.07 (7\%), $0.33(33 \%)$ and $0.0(0 \%)$, respectively. This shows that the SUFI-2 did not capture the observations well during daily and monthly calibration time step although the $\mathrm{R}^{2}$ and NSE were ranged for good agreement. The reason behind high uncertainty of simulated flow for daily and monthly time step might be due to errors in input data such as rainfall and temperature. Further, soil characteristics might also responsible for some uncertainty over simulated results. The model was calibrated with available measured data, but number of years are less that might also trigged to more errors.

During the validation from 2015-2016 the $p$ factor and r-factor for daily, monthly and annual were $0.85,0.17$ and 1 , respectively. Whereas r-factor for daily, monthly and annual time step were 0.05 (5\%), 0.24(24\%) and 0 , respectively. The results indicated that model simulated for daily and annually with less uncertainties, while during monthly more uncertainties were recorded. The reason could be occurrence of long dry spell in between the runoff events could lead to sudden change in AMC which in turn reflected on $\mathrm{CN}$. Another possible reason might be less number of runoff events during the validation period. The varied uncertainty level (0.17 to 1.0$)$ explains why there was more uncertainty in monthly calibration of stream flow which is also in agreement with findings of Sahu et al., 2016.

The dot plots (Fig. 11) obtained from last iteration of calibration process, showing the relationship between parameter values and objective function (NS) values were also analyzed for daily discharge during validation period. The plot shows the distribution of the sampling points as well as their parameter sensitivity. These plots illustrate that all of these parameters generated a range of values with similar model efficiency i.e. NS values in the range of 0.60 to 0.65 and the equifinality phenomenon was very obvious, consequently, it was difficult to extract a proper set of parameters from the dot plots, it is evident that main source of uncertainty resided in the model parameters, but it should be noted that non identifiability of a parameter does not indicate that the model is not sensitive to the parameter (Tanveer Abbas, 2016).

For hydrological prediction, such as discharge, a careful model calibration is 
required for an efficient result. For a good modeling practice, it is required to report the uncertainties in the model prediction along with the results. In this study, SWAT model was applied in the Patapur micro-watershed to simulate stream flow in the period 2012 to 2016 by following a rigorous calibration and validation analysis using the SUFI-2 technique. SUFI-2 is a popular algorithm which estimates the sensitivity and uncertainty of a hydrological model. Thus, it is beneficial in communicating fairly accurate results to the end-users and in obtaining persuasive model predictions. The outcomes of the sensitivity and uncertainty analysis using SWAT and SUFI-2 indicate that the model is appropriate for stream flow prediction in the Patapur micro-watershed. The results of this study indicate that the SWAT-CUP is useful in forecasting flow and estimating underlying uncertainties and related assumptions in the field of water resources. Based on the final results of calibration and validation, the model has closely simulated the observed stream flow. The results of this study would be practical in agricultural water management and soil and water conservation, as well as in mitigating natural hazards such as drought and flood. This calibrated model can be used in further assessment of climate change and land use/land cover impact assessment on water resources. It is suggested in future studies, to use more uncertainty techniques in model calibration, sensitivity and uncertainty analysis.

\section{References}

Abbas Tanveer, Nabi Ghulam, W. Boota Muhammad, Hussain Fiaz, I. Azam Muhammad, Jun Jin Hui, Faisal Muhammad, 2016, Uncertainty analysis of runoff and sedimentation in a forested watershed using sequential uncertainty fitting method. Sciences in Cold and Arid Regions, 8(4): 297-310.
Abbaspour K., Johnson C., Van Genuchten M.T., 2004. Estimating uncertain flow and transport parameters using a sequential uncertainty fitting procedure. Vadose Zone J., 3:1340-1352

Arabi Mazdak, Jane, R. Frankenberger, Bernie, A. Engel and Jeff, G. Arnold, 2008, Representation of agricultural conservation practices with SWAT. Hydrol. Processes, 22: 3042-3055.

Arnold, J. G. and Allen, P. M., 1996, Estimating hydrologic budgets for three Illinois watersheds. J. Hydrol., 176(1-4): 57-77.

Arnold, J. G. and Fohrer, N., 2005, SWAT2000: Current capabilities and research opportunities in applied watershed modelling. Hydrol. Process. 19(3): 563-572.

Arnold, J. G., Srinivasan, R., Muttiah, R. S. and Williams, J. R., 1998, Large area hydrologic modeling and assessment Part-I: Model development. J. Am. Water Resour. Assoc., 34(1): 73-89.

Beven, K., Binley, A., 1992. The future of distributed models: model calibration and uncertainty prediction. Hydrol. Process, 6: 279-298.

Beven, K.J., 2000, Rainfall-Runoff Modeling: the Primer. John Wiley \& Sons: New York.

Duan, Q, Sorooshian, S, Gupta, V.K., 1992, Effective and efficient global optimization for conceptual rainfall-runoff models. Water Resour. Res., 28(4): 1015-1031.

Ganga Ram, M., Youn, S. P., Nam, W. K., Dong, S. S., Jae, W. G., Woo H. J., Jeon Y. S. and K Young, J. L., 2013, Evaluation of SWAT sub-daily runoff estimation at small agricultural watershed in Korea. Environ. Sci. Engg., 7(1): 109-119.

Gassman, P. W., Reyes, M. R., Green, C. H. and Arnold, J. G., 2007, The Soil and Water Assessment Tool: Historical development, applications and future research directions. Trans. of $A S A B, 50(4): 1211-1250$.

Gupta, H, V., Beven, K.J. and Wagener, T., 2006, Model calibration and uncertainty estimation. Encycl. Hydrol. Sci., 11:131.

Gupta, H.V, Sorooshian S., Yapo P.O., 1999, Status of automatic calibration for hydrologic models: comparison with multilevel expert calibration. J. Hydrol. Engg., 4(2): 135-143. 
King, K. W., Arnold J. G. and Bingner R. L., 1999, Comparison of green-ampt \& curve number methods on Goodwin creek watershed using SWAT. Trans. ASAE, 42(4): 919-925.

Luo Y, He C, Sophocleous M, Yin Z, Hongrui R, Ouyang Z., 2008, Assessment of crop growthand soil water modules in SWAT2000 using extensive field experiment data in an irrigation district of the Yellow River Basin. J. Hydrol., 352: 139-156.

Monteith, J. L., 965, Evaporation and environment. $19^{\text {th }}$ Symposia of the society for experimental biology: The State and Movement of Water in Living Organisms. Cambridge University Press, London, p. 205234.

Neitsch, S. L., Arnold, J. G., Kiniry, J. R., Williams, J. R., 2005, Soil and water assessment tool-theoretical documentationversion.

http://swatmodel.tamu.edu/documentation.

Rostamian, R., Jaleh, A., Afyuni, M, Mousavi, S. F., Heidarpour, M, Jalalian, A, Abbaspour, K. C., 2008, Application of a SWAT model for estimating runoff and sediment in two mountainous basins in central Iran. Hydrol. Sci. J., 53:977-988.

Sahu, M., Lahari, S., Gosain, A. K. and Ohri, A., 2016, Hydrological modeling of Mahi basin using SWAT. J. Water Resour. and Hydraulic Engg., 5(3): 68-79.

Shen, Z.Y., Gong, Y.W., Li, Y.H., Hong, Q., Xu, L., Liu, R.M., 2009, A comparison of WEPP and SWAT for modeling soil erosion of the Zhangjiachong watershed in the three Gorges reservoir area. Agricl. Water Manage., 96(10): 1435-1442.

Srinivasan, R., Ramanarayanan, T. S., Arnold, J. G. and Bednarz, S. T., 1998, Large-area hydrologic modelling and assessment: Part II. Model application. J. Am. Water Resour. Assoc. 34(1): 91-101.
Srivastava PK, Han D, Rico-RamirezMA, AlShrafany D, Islam T (2013c) Data fusion techniques for improving soil moisture deficit using SMOS satellite and WRF-NOH land surface model. Water Resour. Manage., 27:5069-5087.

Tang, J, Yang, W, Z-y L, J-m B, Liu, C., 2012, Simulation on the inflow of agricultural nonpoint sources pollution in Dahuofang reservoir catchment of Liao river. J. Jilin Univ., 42:1462-1468.

Vanrolleghem P A et al., 2003, A comprehensive model calibration procedure for activated sludge models. Proc.Water Environ. Fed., 210-237

Vrugt J.A., Gupta H.V, Bouten W, Sorooshian S. 2003. A Shuffled Complex Evolution Metropolis algorithm for optimization and uncertainty assessment of hydrologic model parameters. Water Resour. Res. 39(8): 1201.

Vrugt, J. A, Ter Braak, C.J, Clark, M.P, Hyman, J. M, Robinson, B.A., 2008, Treatment of input uncertainty in hydrologic modeling: doing hydrology backward with Markov chain Monte Carlo simulation. Water Resour. Res., 44.

Wagener, T, Gupta, H.V., 2005, Model identification for hydrological forecasting under uncertainty. Stoch. Env. Res. Risk, 19:378-387.

White, K. L., and Chaubey, I., 2005, Sensitivity analysis, calibration, and validations for a multisite and multivariable SWAT model. $J$. Am. Water Resour. Assoc., 41(5): 1077-1089.

Williams, J. R., 1975, Sediment routing for agricultural watersheds. Water Resour. Bull. 11(5): 965-974.

Yang, J., Reichert, P., Abbaspour, K.C., Xia, J. and Yang, H., 2008, Comparing uncertainty analysis techniques for a SWAT application to the Chaohe basin in China. J. Hydrol., 358: 1-23.

\section{How to cite this article:}

Premanand, B.D., U. Satishkumar, B. Maheshwara Babu, S.K. Parasappa, Mallikarjuna M. Dandu, Ibrahim Kaleel, N.L. Rajesh and Biradar, S.A. 2018. QSWAT Model Calibration and Uncertainty Analysis for Stream Flow Simulation in the Patapur Micro-Watershed Using Sequential Uncertainty Fitting Method (SUFI-2). Int.J.Curr.Microbiol.App.Sci. 7(04): 831-852. doi: https://doi.org/10.20546/ijcmas.2018.704.092 